\title{
Comparison of HEp-2 and Vero Cell Responses Reveal Unique Proapoptotic Activities of the Herpes Simplex Virus Type $1 \alpha 0$ Gene Transcript and Product
}

\section{OPEN ACCESS}

Edited by:

Randall J. Cohrs,

University of Colorado Denver.

United States

Reviewed by:

James R. Smiley,

University of Alberta, Canada

Igor Jurak,

University of Rijeka, Croatia

Chiharu Graybill,

University of Colorado Denver,

United States

*Correspondence: John A. Blaho jblaho@cuny.edu

Specialty section:

This article was submitted to

Virology,

a section of the journal

Frontiers in Microbiology

Received: 28 September 2018

Accepted: 18 April 2019

Published: 08 May 2019

Citation:

Nguyen ML, Gennis E, Pena KC and Blaho JA (2019) Comparison of HEp-2 and Vero Cell Responses Reveal Unique Proapoptotic Activities of the Herpes Simplex Virus Type 1 $\alpha 0$ Gene Transcript and Product. Front. Microbiol. 10:998. doi: 10.3389/fmicb.2019.00998

\section{Marie L. Nguyen', Elisabeth Gennis ${ }^{2}$, Kristen C. Pena ${ }^{2}$ and John A. Blaho ${ }^{3 *}$}

${ }^{1}$ Department of Microbiology and Immunology, Des Moines University, Des Moines, IA, United States, ${ }^{2}$ Department of Microbiology, Mount Sinai School of Medicine, New York, NY, United States, ${ }^{3}$ NYC Regional Innovation Node, The City University of New York, New York, NY, United States

Previous studies have provided evidence suggesting a role for apoptosis in the control of Herpes Simplex Virus 1 (HSV-1) latency. HSV-1 induces and then later blocks apoptosis in infected cells. The immediate early viral gene $\alpha 0$, which synthesizes the ICPO protein, is necessary and sufficient for HSV-1-induced apoptosis in human epithelial (HEp-2) cells. While previous research showed that ICPO protein synthesis is not necessary for HSV-1-induced apoptosis in infected HEp-2 cells, circumstantial evidence suggested that it might be needed in infected African green monkey kidney (Vero) cells. In this study, we determined the specific aspects of $\alpha 0$ needed to trigger apoptosis in these two cell types. HEp-2 cells transfected with $\alpha 0$ expressing plasmids that generated either fulllength, truncated, or no detectable (multiple stop codons) ICPO protein died through apoptosis. This indicates that ICPO protein is not necessary for $\alpha 0$-induced apoptosis and that $\alpha 0$ mRNA alone has apoptotic induction properties in HEp-2 cells. We next investigated the primary structure of $\alpha 0$ 's mRNA to better define its proapoptotic ability. Since $\alpha 0$ is one of the few HSV-1 genes that are spliced, we transfected cells with a plasmid expressing ICPO from cDNA copy, pcDNAICPO. The cells transfected with pcDNAICPO underwent apoptosis at a level equivalent to those transfected with the genomic copy of $\alpha 0$, which indicates that neither splicing events nor introns are required for the apoptotic function of $\alpha 0$ in HEp-2 cells. Next, we studied the ability of $\alpha 0$ to cause apoptosis in Vero cells. Since HSV-1-induced apoptosis in Vero cells requires protein synthesis early in infection, proteins synthesized with immediate early kinetics may facilitate apoptosis. Vero cells were transfected with plasmids producing either fulllength ICPO or ICPO truncated at codon 212. Full-length ICPO, but not truncated ICPO, induced apoptosis in Vero cells. Together, these results suggest that $\alpha 0$ gene expression triggers apoptosis, but ICPO protein is needed to facilitate apoptosis in Vero cells. In addition, ICPO's facilitation activity may lie in its carboxyl-terminated domain. Thus, our results demonstrate that $\alpha 0$ 's mRNA and protein possess proapoptotic properties. The requirement for ICPO protein during HSV-dependent apoptosis appears to be cell type specific.

Keywords: apoptosis induction, $\alpha 0$ gene, ICPO protein, HEp-2, Vero cells 


\section{INTRODUCTION}

Herpes simplex virus 1 (HSV-1) is a large, enveloped DNA virus belonging to the Herpesviridae family. The most common clinical manifestation of HSV-1 infections is herpes labialis, commonly referred to as a cold sore. However, when the virus enters tissues outside of the oral epithelium, more serious disease outcomes occur. For example, HSV-1 infections of the cornea cause herpes simplex keratitis, which is the leading cause of infectious blindness in the United States (Liesegang et al., 1989). Furthermore, neonatal HSV infections often spread to the brain, causing life threatening encephalitis. The majority of neonate infections are the result of HSV transmission from maternal genital infections to newborn infects during childbirth. There has been an increase in genital HSV-1 infections in young women in the United States (Peña et al., 2010). Therefore, insights in the HSV replication cycle have the potential to significantly impact human disease.

One of the defining features of the Herpesviridae family is the ability to form a latent state, from which reactivation events lead to subsequent virus replication and often clinical symptoms. HSV establishes a latent infection in the sensory neurons located at the sites of initial infection, e.g., trigeminal ganglia for oral HSV infections. Reactivation events throughout the lifespan of infected individuals lead to new rounds of lytic virus replication in adjacent epithelial tissues and recurrent herpetic lesions. There is evidence for cellular apoptotic events playing a role in controlling the latent and lytic states of the HSV life cycle (reviewed in Nguyen and Blaho, 2007).

Apoptosis is a form of programmed cell death that has been shown to be important for proper tissue development, prevention of tumors, and cellular responses to pathogens (reviewed in Koyama et al., 2003). Apoptotic cell death is distinguished from other forms of cell death by defined morphological and biochemical features displayed by the dying cells. These features include blebbing and alterations in the chemical makeup of the plasma membrane, condensation and eventual fragmentation of the chromosomal DNA, and loss of mitochondrial membrane potential (Kerr et al., 1972; Wyllie et al., 1980; Takano et al., 1991). One class of enzymes required for most forms of apoptotic cell death are the caspases (reviewed in Salvesen and Dixit, 1997; Villa et al., 1997). Caspases are synthesized as large inactive precursors, which are cleaved and form active tetramers during apoptosis. The caspases cleave their targets at specific peptide motifs containing aspartate residues. Caspase targets include caspases themselves and a variety of other cellular proteins, many which are involved in maintaining the structural or chemical integrity of the cell, e.g., lamin $\mathrm{B}, \mathrm{DFF} / \mathrm{ICAD}$, and poly(ADP)ribose polymerase (PARP) (reviewed in Sanfilippo and Blaho, 2003).

There are two types of gene products abundantly produced during HSV latency. Both are transcripts from the $\mathrm{R}_{\mathrm{L}}$ and surrounding regions of the genome. The long transcripts have been the most well-studied and are called the latency associated transcripts (LATs) (Stevens et al., 1987; Spivack and Fraser, 1988). More recently, microRNAs have also been found to be produced during latent infection (reviewed in Phelan et al., 2017). Infections with recombinant viruses harboring LAT deletions have been reported to yield reduced numbers of latently infected neurons compared to wild-type (Sawtell and Thompson, 1992; Thompson and Sawtell, 1997). Other studies reported a reduced ability for LAT mutants to reactivate from latently infected explants (Leib et al., 1989a). LATs have been shown to possess anti-apoptotic activities (Perng et al., 2000; Inman et al., 2001a; Ahmed et al., 2002; Jin et al., 2003). The anti-apoptotic regions of LATs have been correlated with the domains needed for latency (Perng et al., 2000; Inman et al., 2001a; Ahmed et al., 2002). Furthermore, replacement of LAT domains with other anti-apoptotic genes, such as the bovine herpesvirus $1 \mathrm{LR}$ and Baculovirus cpIAP, restore LAT latency functions in rabbit and mouse HSV infection models (Perng et al., 2002; Jin et al., 2005, 2008). Finally, inducting apoptosis in latently infected trigeminal ganglia with dexamethasone accelerated their reactivation (Du et al., 2012). Thus, investigations into apoptosis in HSV-1 infected cells may provide insight into the establishment, maintenance, and/or reactivation from latency.

Previous studies have provided evidence that an intricate balance between apoptotic agonists and antagonists exists within herpes simplex virus-infected cells in both tissue culture and animal models (Nguyen and Blaho, 2009). Seven viral genes have been reported to possess apoptotic antagonistic properties. When these antagonists are not efficiently produced, such as infections in the presence of protein synthesis inhibitors or in the absence of key immediate early genes (vBS $\Delta 27$ infection) the apoptotic balance is upset, and the infected cells die through the intrinsic apoptotic pathway (Aubert et al., 2007).

The trigger of this HSV-dependent apoptosis has been mapped to the HSV-1 $\alpha 0$ gene (Sanfilippo and Blaho, 2006). Initial studies into the viral factors triggering apoptosis in HEp-2 cells utilized the protein synthesis inhibitor, cycloheximide (CHX) (Aubert and Blaho, 1999). The human carcinoma HEp-2 cells infected in the presence of CHX underwent apoptosis, suggesting that at least in these cells, triggering of HSV-dependent apoptosis does not require de novo protein synthesis. Further studies using actinomycin D or a recombinant virus lacking all immediate early genes (IE), d109, demonstrated that IE gene transcription was required to trigger apoptosis during infection (Sanfilippo et al., 2004a). HSV encodes four immediate early genes, $\alpha 4, \alpha 27, \alpha 22$, $\alpha 0$. Infections with recombinant viruses containing mutations in the $\alpha 4$ (Cgal $\Delta 3), \alpha 27$ (vBS $\Delta 27)$, or $\alpha 22$ (R7802) gene maintained the ability to trigger HSV-dependent apoptosis. In contrast, infection with a recombinant virus lacking expression of the $\alpha 0$ gene (7134) failed to induce apoptosis (Sanfilippo and Blaho, 2006). Furthermore, a virus lacking expression of all immediate early genes except for $\alpha 0, d 106$, maintained the ability to trigger apoptosis. The $\alpha 0$ gene encodes a multifunctional protein of $110 \mathrm{kDa}$ in size, ICP0 (reviewed in Everett, 2000; Hagglund and Roizman, 2004). In HEp-2 cells, infection with a virus containing a nonsense mutation at amino acid 212 of ICP0 (n212), which was therefore, unable to produce full length ICP0 protein, was still capable of inducing apoptosis. Finally, one series of experiments determined that expression of ICP0 from a plasmid outside of an HSV infection induced apoptosis in a dose dependent manner in HEp-2 cells (Sanfilippo and Blaho, 2006). Together, these studies demonstrated that the ability of HSV to trigger apoptosis within 
infected cells maps to the $\alpha 0$ gene, and that translation of the fulllength protein was not required for induction of HSV-dependent apoptosis in HEp- 2 cells. The $\alpha 0$ gene is located in the long repeat regions of the HSV-1 genome and is unique compared to other HSV-1 genes in that it contains three exons and two introns (Figure 1, line 2). $\alpha 0$ is also unique because the spliced introns remain stable in the cytoplasm and accumulate in a cell-typedependent manner (Carter and Roizman, 1996). In this study, we go on to further investigate the nature of $\alpha 0$ 's pro-apoptotic activities in HEp-2 cells.

We also expanded our analysis to investigate the role of $\alpha 0$ and ICP0 in apoptosis in primate kidney Vero cells, which have been previously been shown to possess different requirements for HSV-dependent apoptosis compared to HEp-2 cells (Nguyen et al., 2005). Vero cells undergo HSV-dependent apoptosis when infected with the vBS $\Delta 27$-mutant virus, but, unlike HEp-2 cells, fail to undergo apoptosis when infected with wild-type HSV in the presence of cycloheximide. In fact, cycloheximide treatment at or before $3 \mathrm{hpi}$ suppressed the apoptosis induced by vBS $\Delta 27$ infection. This data led to the conclusion that as opposed to HEp-2 cells, Vero cells require de novo synthesis of a protein produced by $3 \mathrm{hpi}$ in order to undergo HSV dependent apoptosis. This protein was named the facilitator of apoptosis (FAP), due to its key role in viral apoptosis (Nguyen et al., 2005). FAP could be either a cellular protein produced prior to $3 \mathrm{hpi}$, or one of the immediate early proteins. In this study we explore whether the ICP0 protein itself can facilitate viral apoptosis during HSV infection in Vero cells.

\section{MATERIALS AND METHODS}

\section{Cell Lines and Viruses}

Human epithelial (HEp-2) and African green monkey kidney (Vero) cells were obtained from the American Type Culture Collection (Rockville, MD, United States). It has been shown that the HEp-2 strain, which was previously described to be derived from laryngeal carcinoma, is a HeLa contaminant; we have referred to this HeLa-derived strain as HEp-2 (Nguyen et al., 2005). Vero and HEp-2 cells were cultured in Dulbecco's modified Eagle's medium (DMEM) and supplemented with 5\% fetal bovine serum (FBS). FO6 cells are a Vero derivative, which express the ICP0, ICP4, and ICP27 genes from their respective viral promoters (Samaniego et al., 1998). FO6 cells were grown in DMEM supplemented with 5\% FBS containing $400 \mu \mathrm{g} / \mathrm{ml} \mathrm{G} 418$ and $300 \mu \mathrm{g} / \mathrm{ml}$ hygromycin. The Vero-derived cell line expressing ICP0 from its viral promotor, L7 (Samaniego et al., 1998), was grown in DMEM supplemented with 5\% FBS containing $400 \mu \mathrm{g} / \mathrm{ml} \mathrm{G} 418$. HSV-1 strain KOS1.1 (KOS) and HSV-1 strain $17+(17)$ are the wild-type strains of HSV-1 used in this study. The HSV-1 mutant, vCPc0, was generously provided by Dr. Saul Silverstein (Columbia University) and has both ICP0 genomic coding regions of 17 replaced by cDNA copies of the ICP0 transcript (Panagiotidis et al., 1997). Vero cells were used for growth and tittering of wild-type HSV-1 strains and of vCPc0. 7134 and n212 viruses were generously provided by Dr. Pricilla Schaffer (Harvard Medical School). 7134 is an ICP0-null virus, which has both copies of ICP0 in KOS replaced by the E. coli lacZ gene (Cai and Schaffer, 1989). This virus was propagated and tittered on FO6 cells. The KOS-derived HSV-1 n212 (n212) contains a stop codon in all three reading frames at amino acid 212 of ICP0 (Cai and Schaffer, 1989). This virus was propagated and tittered on $\mathrm{L} 7$ cells. All virus titers were determined at $48 \mathrm{~h}$ post-infection by standard dilution techniques.

\section{Viral Infection and Protein Synthesis Inhibition by $\mathrm{CHX}$}

HEp-2 cells were seeded in DMEM supplemented with 5\% new born calf serum (NBCS) $24 \mathrm{~h}$ prior to infection. Cells were infected at a multiplicity of infection (MOI) of 10 and incubated at $37^{\circ} \mathrm{C}$ for $1 \mathrm{~h}$. Media was aspirated and replaced with $5 \%$ NBCS and incubated at $37^{\circ} \mathrm{C}$ and $5 \% \mathrm{CO}_{2}$ for $24 \mathrm{~h}$. In experiments designed to inhibit de novo protein synthesis, cycloheximide (CHX) was added directly to the medium of monolayers at a final concentration of $10 \mu \mathrm{g} / \mathrm{ml}$, which has been previously shown to sufficiently block viral protein synthesis in KOS-infected cells (Aubert and Blaho, 1999). One hour prior to infection, CHX is added at $37^{\circ} \mathrm{C}$ and was maintained in the medium until $24 \mathrm{~h}$ postinfection when morphological and biochemical analyses were performed (described below).

\section{Plasmids}

The pSH, pn212, pn12/106, and pn12/212 plasmids were generously provided by Pricilla Schaffer (Harvard Medical School) and were previously described (Cai and Schaffer, 1989). Briefly, pSH includes the entire ICP0 coding region $(3.2 \mathrm{kB})$ as well as the flanking sequences $\left(0.81 \mathrm{kB} 5^{\prime}\right.$ and $\left.0.4 \mathrm{kB} 3^{\prime}\right)$ in a pUC8 backbone and for clarity in this study is hereafter referred to as pICP0 (Figure 1, line 6). The plasmid expressing ICP0 from a cDNA copy of ICP0 in pUC19, pDS-16 (Panagiotidis et al., 1997), was generously provided by Saul Silverstein (Columbia University) and hereafter is referred to as pcDNAICP0 (Figure 1, line 7). pn212 is a derivative of pICP0 (Cai and Schaffer, 1989) containing a stop codon in all three reading frames at amino acid 212 and therefore generates full-length $\alpha 0$ transcript and a truncated ICP0 protein, referred to as pTruncICP0 (Figure 1, line 8). p $\alpha 0$ RNAn12/106 (Figure 1, line 9) and p $\alpha 0$ RNAn12/212 (Figure 1, line 10) are related to pTruncICP0 and contain additional stop codons at a.a. 12 and 106 or 212 respectively. In pICP0, pcDNAICP0, pTuncICP0, p $\alpha 0$ RNAn12/106, and $\mathrm{p} \alpha 0 \mathrm{RNAn} 12 / 212$, ICP0 synthesis is regulated by the viral $\alpha 0$ promotor, which is contained in the $5^{\prime}$ flanking region.

pICP0GFP simultaneously expresses ICP0 and the efficient green fluorescent protein (GFP) from the same transcript. To create it, an internal ribosome entry site (IRES) and the GFP gene from the $\mathrm{pHR}^{\prime}$-CMV MCS IRES GFP delta B plasmid (generously obtained from Mary Klotman, Mount Sinai School of Medicine), were cloned directly after the ICP0 $3^{\prime}$ flanking region of the pICP0 plasmid (Figure 1, line 11). pcDNAICP0GFP (Figure 1, line 12) and p $\alpha 0 \mathrm{RNAn12/106GFP} \mathrm{(Figure} \mathrm{1,} \mathrm{line} \mathrm{13)}$ were created by replacing the ICP0 in pICP0GFP with the cDNA and $\alpha 0$ RNAn $12 / 106$ versions. The BAK plasmid (pBAK) was obtained from Peter Palese (Mount Sinai School of Medicine) and 


\section{Schematic representation of ICP0 constructs}

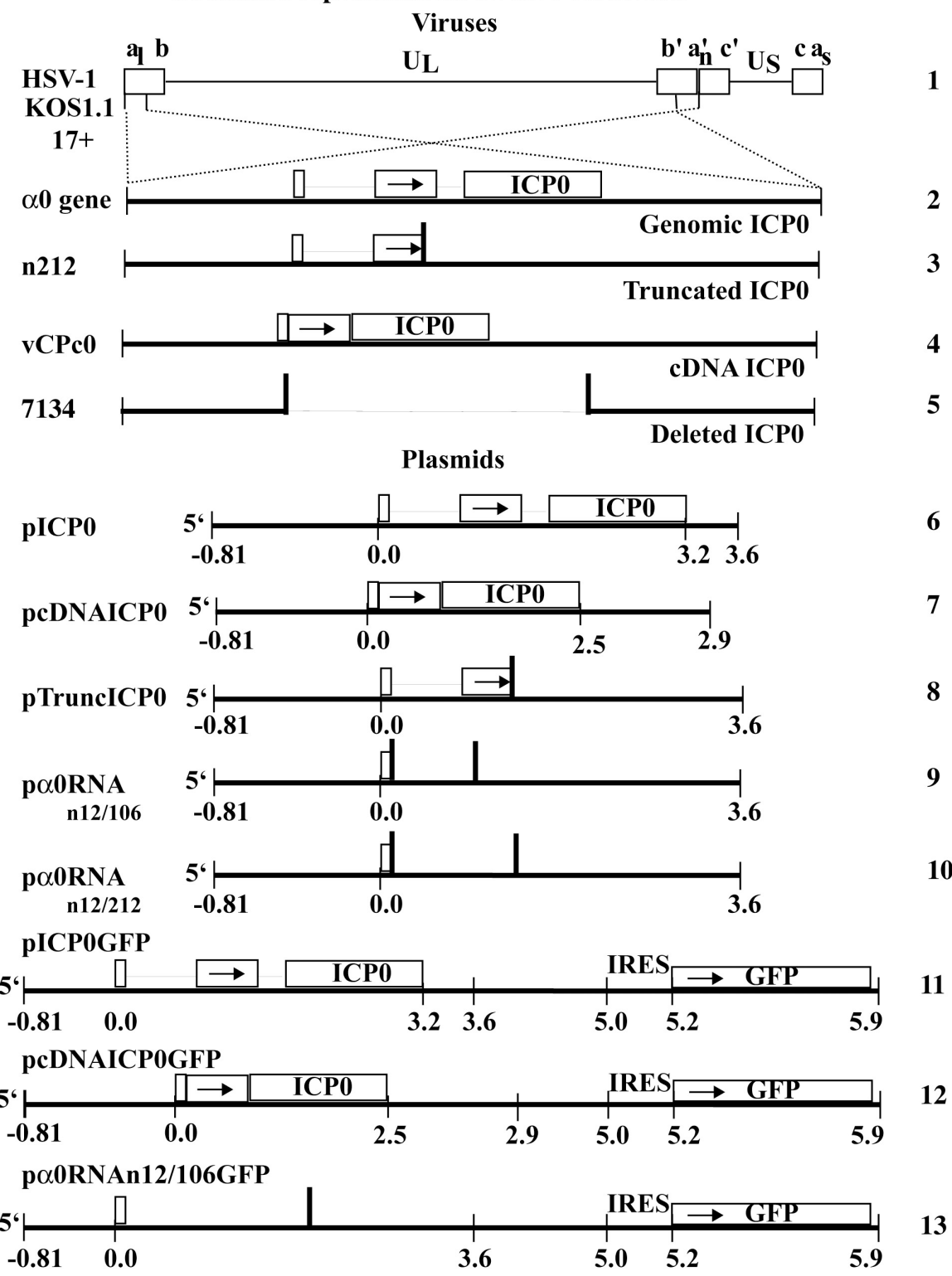

FIGURE 1 | Schematic representation of HSV-1 viral constructs and ICPO plasmids. HSV-1 (line 1) contains two copies of the $\alpha 0$ gene (line 2), encoding ICPO, in the inverted repeated regions ( $a b c a^{\prime} b^{\prime} c^{\prime}$ ) that flank the unique long region $\left(U_{L}\right)$ in the HSV-1 genome. The $\alpha 0$ introns and exons are represented by lines and boxes, respectively. The $\mathrm{n} 212$ virus generates full-length $\alpha 0$ mRNA but a truncated ICPO protein. It contains the same $\alpha 0$ sequences as wild-type HSV-1 but there are nonsense mutations in all three reading frames inserted after codon 212 in both copies of ICPO (line 3). The vCPc0 virus generates cDNA-expressed ICPO protein from both copies of $\alpha 0$ (line 4). The 7134 virus contains deletions of both copies of $\alpha 0$ and does not produce ICPO (line 5). The pICP0 plasmid contains the entire genomic ICPO coding region and flanking sequences (810 bases and $0.4 \mathrm{kB}$ at the $5^{\prime}$ and $3^{\prime}$ ends, respectively) within the pUC8 vector (line 6 ). The pcDNAICP0 plasmid includes the CDNA copies of ICPO and flanking sequences from ICPO coding region (810 bases and $1.1 \mathrm{kB}$ at the $5^{\prime}$ and $3^{\prime}$ ends, respectively) within the pUC19 vector (line 7). pTruncICPO generates full-length ICPO mRNA and a truncated protein due to a nonsense mutation after codon 212 (line 8). paORNAn12/106 contain nonsense codons at a.a. 12 and 106 (line 9). paORNAn12/212 contain nonsense codons at a.a. 12 and 212 (line 10). pICP0GFP contains an internal ribosome entry site (IRES) and the efficient green fluorescent protein (GFP) immediately following the ICPO gene of pICPO (line 11). Similarly, pcDNAICP0GFP and paORNAn12/106GFP contain the IRES-GFP inserted into pcDNAICP0 and paORNAn12/106, respectively (lines 12 and 13).

expresses an HA-tagged BAK protein from the CMV promotor. pUC19 was obtained from New England Biolabs. In several previous studies, the amount of apoptosis in DNA-negative, control transfected cells is undetectable (Goodkin et al., 2003; Sanfilippo et al., 2004a,b; Sanfilippo and Blaho, 2006).

\section{Transfections}

HEp- 2 and Vero cells were seeded at $2.5 \times 10^{5}$ cells $/ 2 \mathrm{~cm}^{2}$-surface area dish in DMEM containing 5\% FBS and transfected $24 \mathrm{~h}$ later (approximately 80\% confluence) using Lipofectamine 2000 (Invitrogen) according to the manufacturer's protocol. Briefly, 
purified plasmid DNA (0.4 and $1.0 \mu \mathrm{g}$, respectively) was diluted in $25 \mu \mathrm{l}$ DMEM. Lipofectamine 2000 reagent $(1.0$ and $1.5 \mu \mathrm{l}$, respectively) was diluted in $25 \mu \mathrm{l}$ DMEM. After $5 \mathrm{~min}$, the diluted Lipofectamine was added to the DNA solution, and complexes formed at room temperature for $20 \mathrm{~min}$. The media was aspirated off cell monolayers and replaced with $200 \mu \mathrm{l}$ DMEM, and $50 \mu \mathrm{l}$ of the DNA-Lipofectamine complex solution was added to each well. Cells were incubated at $37^{\circ} \mathrm{C}$ and $5 \% \mathrm{CO}_{2}$ for 4 to $6 \mathrm{~h}$ when the media was aspirated and replaced with DMEM supplemented with $10 \%$ FBS and incubated until the time of harvest, as denoted in the text.

\section{Microscopic Analyses and Quantification of Chromatin Condensation}

Infected and transfected cell phenotypes were documented using phase-contrast light microscopy with an inverted fluorescence microscope. Images were obtained using QCapture software. For analysis of chromatin condensation in live cells, the DNA dye, Hoechst 33258 (Sigma), was added to media at a final concentration of $5 \mu \mathrm{g} / \mathrm{ml}$ for at least $1 \mathrm{~h}$ at $37^{\circ} \mathrm{C}$. Phase-contrast (phase) and fluorescent (Hoechst and/or GFP) images were taken for each well. Merged (overlay) images were generated using Adobe Photoshop CS software. The percentage of nuclei containing condensed chromatin to total cells was determined for triplicate wells and the mean (M) and standard deviation (SD) of apoptotic cells were determined for each treatment. Typically, 100-300 cells were counted for each well. For HEp-2 experiments, raw data from five experiments with identical conditions was pooled and overall $\mathrm{M}$ and SD were determined:

$i=$ Treatment, $j=$ Well

$$
\begin{gathered}
M_{i}^{H E p-2}=\left(\frac{\sum \text { CondensedChromatin }_{i}}{\sum \text { TotalCell }_{i}}\right) \\
S D_{i}^{H E p-2}=\sqrt{\frac{\sum\left(\frac{\text { CondendedChromatin }_{i j}}{\text { TotalCells }_{i j}}-M_{i}\right)^{2}}{\text { TotalCells }_{i}}}
\end{gathered}
$$

Since Vero experiments were done in a time course, data from each time-point was standardized by dividing the percentage of apoptotic cells for each treatment by the percentage of apoptotic cells in pUC19-transfected cells. The $M$ and SD was calculated from three independent experiments using the following formula:

$i=$ Treatment, $j=$ Well, $k=$ Time Point

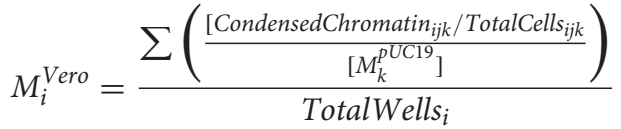

$$
\begin{aligned}
& S D_{i}^{\text {Vero }}=\sqrt{\frac{\sum\left(\frac{\left[\text { CondensedChromati }_{i j k} / \text { TotalCell }_{i j k}\right.}{\left[M_{k}^{\text {pUC19 }}\right]}-M_{i}\right)}{\text { TotalWells }_{i}}}
\end{aligned}
$$

\section{Cellular Extractions, Denaturing Gel Electrophoresis, and Immunoblotting}

Whole cell extracts were obtained as previously described (Nguyen et al., 2007). Briefly, cells were scraped into the media, combined and collected by centrifugation for $5 \mathrm{~min}$ at $4^{\circ} \mathrm{C}$ and $1000 \times g$. For transfection experiments, cells from three identically treated wells were combined for protein analysis. Pellets were washed in cold phosphate buffered saline (PBS) containing the inhibitors: $2 \mathrm{mM}$ phenylmethylsulfonyl fluoride (PMSF), 1\% Transylol, $0.1 \mathrm{mM} \mathrm{L-1-chloro-3-(4-tosulamido)-}$ 4-phenyl-2butanone (TPCK), and 0.01 mM L-1-chloro-3(4-tosylanmido)-7-aminoheptanonhydrochloride (TLCK). Cells were lysed in RIPA buffer $(50 \mathrm{mM}$ Tris-HCl, pH 7.5, $150 \mathrm{mM} \mathrm{NaCl}, 1 \%$ Triton X-100, 1\% deoxycholate, $0.1 \%$ SDS) containing the inhibitors described above and vortexed for 30 s. Lysates were cleared by centrifugation for $10 \mathrm{~m}$ at $4^{\circ} \mathrm{C}$ and $16,000 \times g$. Protein concentrations were determined using a modified Bradford assay (BioRad) as recommended by the vendor. Equal amounts of cell proteins were separated in denaturing $12 \% \mathrm{~N}, N^{\prime}$-diallyltartardiamide (DATD)-acrylamide gels and electrically transferred to nitrocellulose membranes in a tank apparatus (BioRad). Membranes were blocked for at least $1 \mathrm{~h}$ at room temperature in PBS containing 5\% non-fat dry milk (blocking buffer), washed with Tris-buffered saline containing $0.1 \%$ Tween-20 (TBS-T), and incubated overnight in primary antibody at $4^{\circ} \mathrm{C}$. The mouse monoclonal antibodies anti-PARP (PharMingin), -procaspase-7 (BD Transduction), ICP0 (Goodwin Institute for Cancer Research, Plantation, FL, United States), -VP22 (Blaho et al., 1994), -ICP27 (Goodwin) and -actin (Sigma) were used at a 1:1000 dilution in Trisbuffered saline containing $0.1 \%$ Tween 20 and $0.1 \%$ BSA. Mouse anti-HA monoclonal antibody (Southern Biotech) (to screen for HA-tagged BAK protein) was used at a 1:5000 dilution. After washing with TBS-T, membranes were treated with secondary anti-mouse antibodies conjugated with alkaline phosphatase (AP) (Southern Biotech) or with horseradish peroxidase (HRP) (GE Healthcare) at a 1:1000 dilution in blocking buffer. Membranes treated with AP secondary were developed using AP buffer containing 5-bromo-4-chloro-3-indolyl phosphate and 4-nitrobluetetrazolium chloride. Membranes treated with HRP antibodies were immersed in western blotting substrates (Roche) and exposed to Biomax XAR film (Kodak). Complete blots were cut with razor blades and sections were probed using specific, relevant antibodies. Blots were reassembled and scanned in a single run. The resulting digital images were cropped as necessary to create figures.

\section{Densitometric Analysis}

To quantify PARP and procaspase-7 cleavage densitometry of images was performed and analyzed using NIH image software. For PARP cleavage, the mean density (MD) of the cleaved PARP band was divided by the sum of MD cleaved and MD uncleaved PARP bands and expressed in a percentage: $i=$ Treatment

$$
\%{\text { PARP } \text { cleavage }_{i}}=100 \times\left(\frac{\text { MD }_{\text {cleaved }_{i}}}{\left[M_{\text {uncleaved }_{i}}+M D_{\text {cleaved }_{i}}\right]}\right) .
$$

Procaspase-7 cleavage was determined by dividing MD procaspase-7 band by the $\mathrm{MD}$ of the respective band in the actin loading control. Values were normalized to the pUC19 procaspase-7 to actin ratio to determine percentage of 
procaspase-7 compared to pUC19 as follows. $i=$ Treatment

Normalized \% procaspase-7 Cleavage

$$
=100 \times \frac{\left[M D_{\text {casp } 7_{i}} / M D_{\text {actin }_{i}}\right]}{\left[M D_{\text {casp } 7 p U C 19} / M D_{\text {actinpUC19 } \left._{19}\right]}\right.} .
$$

\section{Statistical Analysis}

To determine statistical significance, Microsoft Excel was used to perform the Student's $t$-test on apoptotic morphology data (Figures 3, 5, 6, 8). p-Values of 0.05 or lower were considered statistically significant.

\section{RESULTS}

\section{Introns Are Not Required for ICP0's Proapoptotic Activity in HEp-2 Cells}

Because $\alpha 0$ appeared able to confer its pro-apoptotic activity through an RNA-mediated mechanism (Sanfilippo and Blaho, 2006), we asked whether the two ICP0 introns are necessary for inducing apoptosis in HEp-2 cells. We tested whether cDNAexpressed $\alpha 0$ induced apoptosis upon HSV-1 infection in the presence of $\mathrm{CHX}$. HEp-2 cells were treated with $\mathrm{CHX}$ and infected with $\mathrm{vCPc} 0$, which is a virus derived from the wildtype HSV-1 strain 17 that generates both copies of ICP0 using the viral promotor and cDNA copies of $\alpha 0$. Infection of HEp2 cells with both wild-type strains of HSV-1, 17 and KOS, in the presence of CHX were used as positive controls. Infection with wild-type HSV-1 strains and $\mathrm{vCPc} 0$ in the absence of CHX and infection with the ICP0-null virus, 7134, in the absence and presence of $\mathrm{CHX}$ were used as negative controls. At $24 \mathrm{~h}$ post-infection, Hoechst DNA dye was added to the media to allow for visualization of chromatin and cellular and nuclear morphologies were assessed. Following imaging, whole-cell extracts were prepared, separated on a denaturing gel, and probed with anti-PARP, -ICP27, -ICP0 and -VP22 antibodies as described in Section "Materials and Methods." VP22 detection is a marker for late phase viral replication (Blaho et al., 1994).

This experiment was repeated twice and the results from a representative experiment are shown in Figure 2. Phase contrast, Hoechst images, and apoptotic cell percentages are displayed in Figure 2A. The morphological results show that cells infected with wild-type HSV-1 strains, vCPc0 and 7134 in the absence of CHX show enlarged cell size and diffuse cytoplasmic DNA patterns indicative of infectious cytopathic effect (CPE). This morphology results when the HSV-1 virus is regulating cellular machinery and generating HSV-1 virions. Eventually, cells are lysed and viral progeny are released. These treatments show very low levels of apoptosis, since HSV-1 generates anti-apoptotic proteins to prevent programmed cell death to result in infected cells. Cells treated with $\mathrm{CHX}$ in the absence of infection show a baseline level of chromatin condensation and membrane blebbing (13\%) due to CHX treatment. Cells infected with ICP0null HSV-1 in the presence of CHX show a baseline level of apoptosis that is slightly increased from $\mathrm{CHX}$ treatment alone
(26\%). This is consistent with previous results (Sanfilippo and Blaho, 2006). KOS and 17 infection in the presence of CHX shows marked increase in apoptotic morphologies (52 and 62\%, respectively). Infection with $\mathrm{vCPc} 0$ in the presence of $\mathrm{CHX}$ shows chromatin condensation and membrane blebbing morphologies at levels (51\%) similar to that of KOS.

Additionally, we assessed biochemical markers for apoptosis. When CHX is not present, all wild-type and mutant HSV1 infections show the presence of VP22, indicating late viral replication and verifying the morphological results (Figure $2 \mathbf{B}$, lanes 2-5). All HSV-1- cells infected in the absence of CHX also generated ICP27 and, with the exception of 7134, ICP0. 7134-infected cells do not generate ICP0 since this is an ICP0null virus. Conversely, wild-type and mutant infections in the presence of CHX did not synthesize VP22, ICP0, and ICP27 (Figure 2B, lanes 7-10). In the presence of CHX, all HSV-1infected cells generate low levels of modified ICP27 compared to infection in the absence of CHX. The production of these ICP27 immune reactive triplet forms was previously reported and is likely due to a unique feature of the ICP27 transcript that allows for translation in the presence of CHX (Sanfilippo et al., 2004b). When the apoptotic marker, PARP, was analyzed in this experiment, all wild-type and mutant HSV-1-infected cells without CHX had low levels of PARP cleavage (lanes 2$5)$. This indicates that little to no apoptosis occurring in these wells, which confirms the morphological results (Figure 2A). CHX-treated cells show baseline PARP cleavage for this treatment (lane 6). 7134-infected cells in the presence of CHX had PARP cleavage similar to $\mathrm{CHX}$-treated cells (compare lane 10 with 6), which indicates that HSV-1 infection without $\alpha 0$ does not induce apoptosis. Whole-cell extracts from KOS- and 17-infected cells in the presence of CHX resulted in nearly complete PARP cleavage (lanes 7-9), indicating high rates of apoptosis and verifying morphological results (Figure 2A). Importantly, vCPc0-infection in the presence of CHX caused PARP cleavage at rates equivalent to KOS-infected cells plus $\mathrm{CHX}$. Together, these morphological and biochemical results indicate that in the absence of protein synthesis intron-less, cDNA-expressed $\alpha 0$ induces apoptosis in infected cells at similar rates to wild-typeinfected cells.

Previous studies have indicated that transfection with a plasmid expressing ICP0 induces apoptosis in cells (Inman et al., 2001b; Sanfilippo and Blaho, 2006). To test whether $\alpha 0$ introns are needed for induction of apoptosis in this setting, we transfected cells with a plasmid expressing ICP0 from a cDNA copy of the $\alpha 0$ gene (pcDNAICP0) and compared the response to cells transfected with a plasmid expressing ICP0 from the intron-containing, genomic copy of the gene (pICP0). The pUC19 plasmid was used as a negative control. In addition, a plasmid (pBAK) expressing the proapoptotic $\mathrm{BCl}$ 2 family member, BAK, which induces the intrinsic apoptotic pathway, was used as a positive control. This experiment was repeated five times in triplicate. At $24 \mathrm{~h}$ post-transfection, cellular and nuclear morphologies were assessed and the results from a representative experiment are displayed in Figure 3A. The overall means and standard deviations of chromatin condensation from all five experiments are graphed in Figure 3B. 
A Cellular and nuclear morphologies - Infected HEp2 cells at 24 hpi

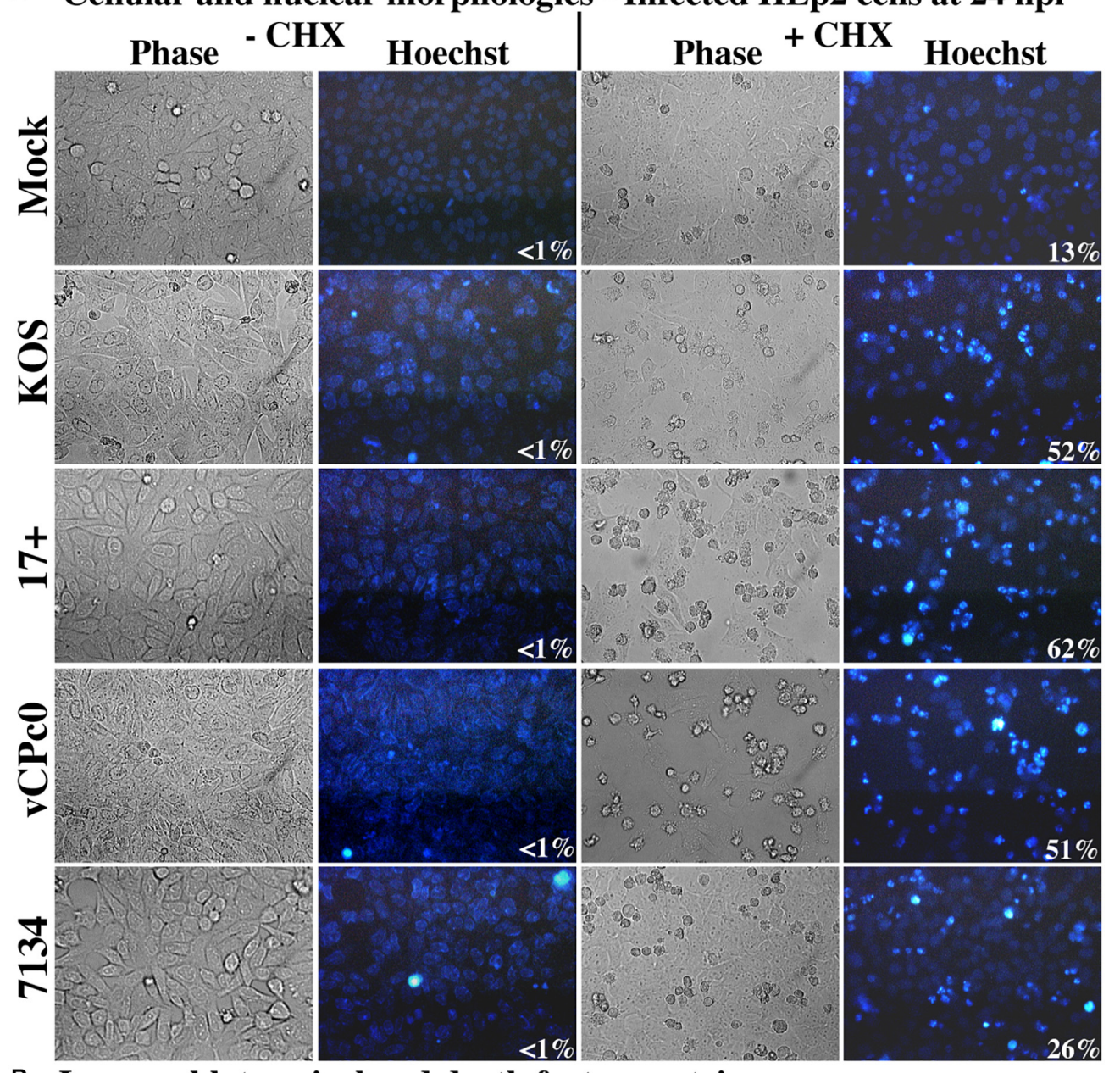

B Immunoblots - viral and death factor proteins

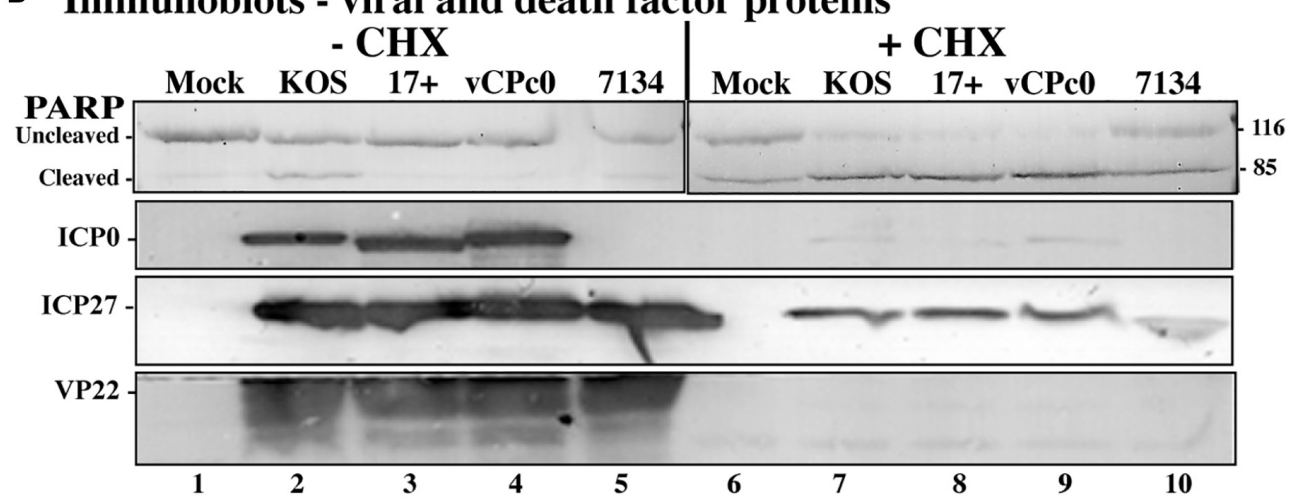

FIGURE 2 | Morphological and biochemical assessment of infected HEp-2 cells at $24 \mathrm{~h}$ post-infection. (A) HEp-2 cells were infected at MOI of 10 with wild-type HSV-1 (KOS), HSV-1 (17+), and recombinant ICPO viruses VCPc0 and 7134. Twenty-four hours following post-infection Hoechst DNA dye was added to the media at a concentration of $5 \mu \mathrm{g} / \mathrm{ml}$ to visualize chromatin condensation. Phase contrast and Hoechst-stained images were obtained at $24 \mathrm{~h}$ post-infection (40X magnification). Numbers in the lower right corner of Hoechst panels represent the percentage of nuclei displaying chromatin condensation in that treatment. (B) Whole-cell extracts were obtained from these cells. Subsequently, the extracted proteins were immunoblotted for PARP, ICPO, ICP27, and VP22. Cropped images of blots were prepared as described in Section "Materials and Methods."

Cells transfected with pcDNAICP0 showed more chromatin condensation $(52.8 \pm 10.3 \%)$ compared to pUC19 transfected cells $(18 \pm 11.4 \%)$. This difference was deemed to be statistically significant $(p<0.05)$ using Student's $t$-test. Cells transfected with positive control plasmids, pICP0 and pBAK, showed levels near and above that for pcDNAICP0, respectively. 


\section{A Cellular and nuclear morphologies - HEp-2 cells at $24 \mathrm{~h}$ post transfection \\ Hoechst Overlay}
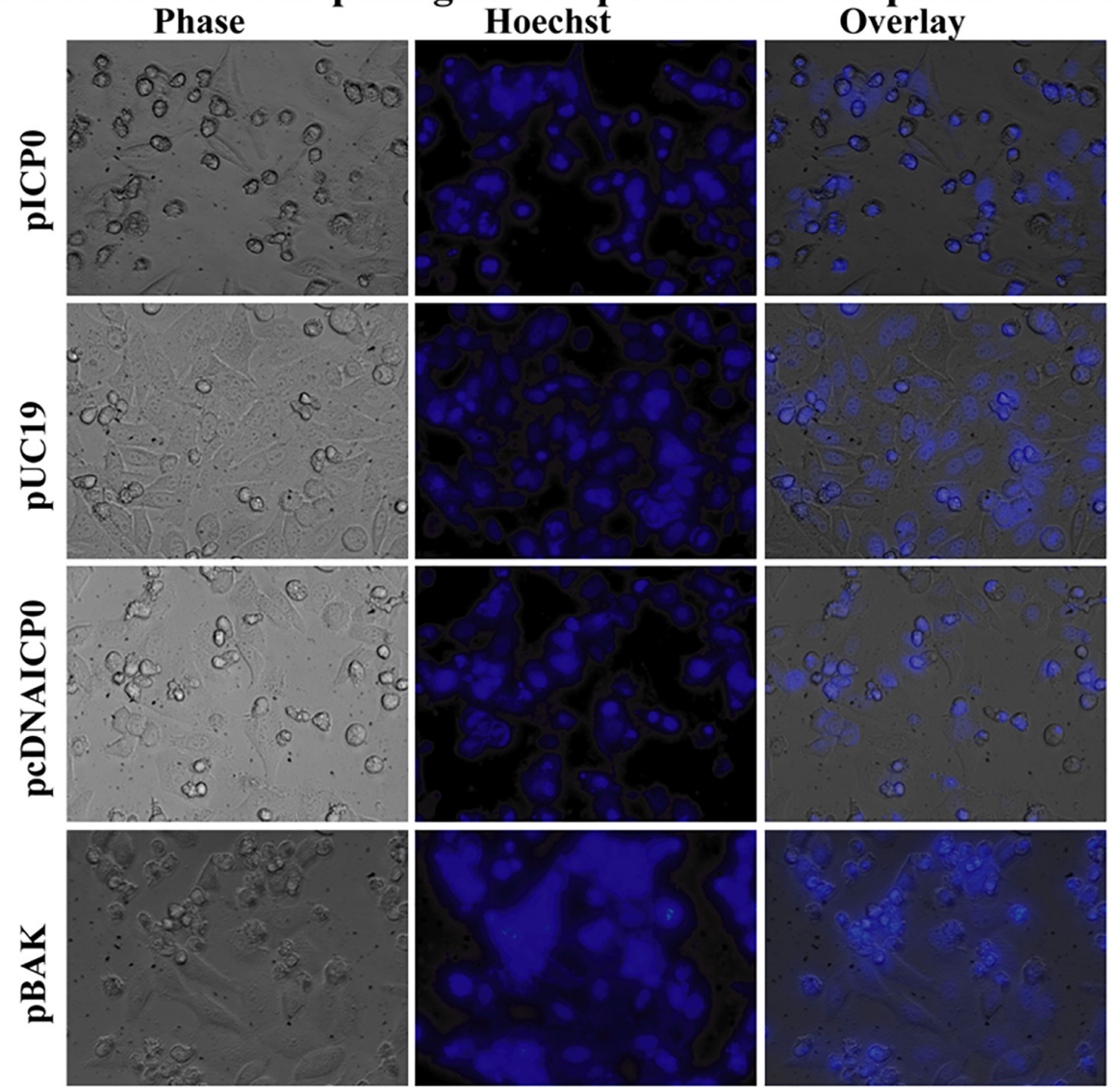

\section{B Statistical analysis of Condensed chromatin}

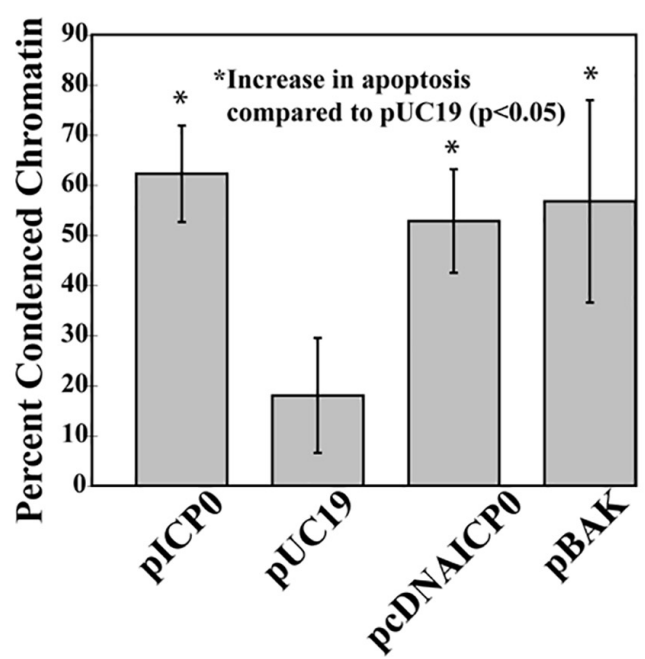

C Immunoblots - HEp-2 proteins after

Transfection

PARP

Uncleaved

Cleaved

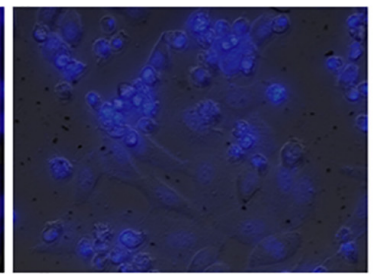

PARP Clvg: $39.97 \quad 24.23 \quad 35.31 \quad 85.54$

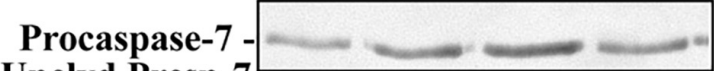
\%Unclvd Presp-7 rel. to pUC19:

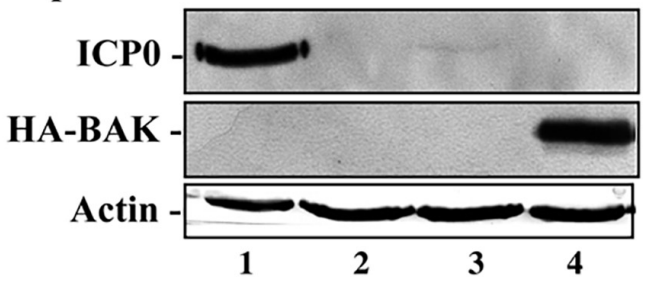

FIGURE 3 | Apoptosis in HEp-2 cells following transfection with plCPO and pcDNA. (A) Cell morphologies of HEp-2 cells transfected with $0.4 \mu \mathrm{g}$ of pICPO, pcDNAICP0, and pBAK. Twenty-four hours following transfection Hoechst DNA dye was added to the media at a concentration of $5 \mu \mathrm{g} / \mathrm{ml}$ to visualize chromatin condensation. Phase contrast, Hoechst-stained, and overlayed images were captured with a digital camera (40X magnification). Images are representative of a single experiment. (B) Statistical analysis of percentages of condensed chromatin for each treatment was conducted using Student's $t$-test ( $p<0.05)$. The results represented in the bar graphs are from five independent experiments performed in triplicate. The mean of the percentage of cells exhibiting chromatin condensation following transfection is graphed. Error bars represent standard deviation for each treatment group. (C) Immune reactivities of transfected cells from triplicate wells 


\section{FIGURE 3 | Continued}

that were combined, harvested, separated in a denaturing gel, transferred to nitrocellulose, probed with anti-PARP, -ICPO, -actin, -procaspase-7 and -HA primary antibodies. PARP and procaspase-7 band intensities were quantified using NIH image software, as described in Section "Materials and Methods." Percent PARP cleavage was calculated as a ratio of the band intensity of cleaved PARP relative to the sum of uncleaved and cleaved bands. For procaspase-7 protein, the band intensity for cells transfected with pUC19 was set to $100 \%$ and all other groups are displayed relative to this number. Cropped images of blots were prepared as described in Section "Materials and Methods."

Previously, we have demonstrated that procaspase-7 is cleaved and activated during HSV-dependent apoptosis (Kraft et al., 2006); we used immunoblots for this and PARP as markers for apoptosis (Figure 3C). Immunoblotting was also used to detect ICP0 and BAK produced in transfected cells. Transfection with pcDNAICP0 led to an increase in PARP cleavage (35.31\%) and a decrease in procaspase-7 protein $(80.22 \%)$ from pUC19 $(24.23 \%$ PARP cleavage and $100 \%$ procaspase- 7 protein). It is of note that the magnitude of biochemical markers for apoptosis in these groups was less than the magnitude of the difference in apoptotic morphologies (Figure 3B). Because we are looking at whole cell lysates from both transfected and non-transfected cells, some of the differences in protein levels can be more difficult to detect, than distinctions in morphologies that are quantitated on a per cell basis. Although pcDNAICP0 produces less ICP0 protein than pICP0 as seen in the ICP0 blot (Figure 3B, compare lane 3 with 1), pcDNAICP0-transfected cells show increased levels of apoptosis from the pUC19 baseline. Based on the results presented in Figures 2, 3, we conclude that the $\alpha 0$ introns are not required for the apoptotic activity of ICP0.

\section{Apoptosis Is Cell-Autonomous in ICPO-Transfected HEp-2 Cells}

The apoptosis induction by $\alpha 0$ transfection could either be explained by ICP0 expression directly causing apoptosis in transfected cells or indirectly causing apoptosis in nearby nonexpressing cells via the secretion of a pro-apoptotic factor. To distinguish between these possibilities, we constructed plasmids expressing either the full-length ICP0 open reading frame or the cDNA version, containing GFP driven from an adjacent IRES, termed pICP0GFP and pcDNAICP0GFP, respectively (Figure 1, lines 11 and 12). Transfecting HEp-2 cells with these GFPexpressing constructs allowed us to identify the cells expressing ICP0 and assess their morphologies. HEp-2 cells were transfected with control GFP-expressing plasmid (pGFP), pcDNAICP0GFP, or pICP0GFP. At $24 \mathrm{~h}$ following transfection, GFP fluorescence, stained chromatin, and morphological changes were assessed using phase contrast and fluorescence microscopy (Figure 4A). Green fluorescence indicative of GFP expression was evident in pGFP-, pcDNAICP0GFP-, and pICP0GFP-transfected cells. The majority of the GFP positive cells from the pGFP transfection displayed a cobblestone morphology and their chromatin was evenly distributed throughout the nuclei, indicative of a healthy cell monolayer, and similar to the morphologies of the surrounding non-transfected cells. In contrast, the majority of the GFP-positive cells from the pcDNAICP0GFP- and pICP0GFPtransfected wells were smaller, exhibited membrane blebbing, and displayed smaller, more brightly stained nuclei than pGFPtransfected cells. These phenotypes are indicative of cells undergoing apoptosis. We quantitated the percentage of GFPpositive cells displaying apoptotic morphologies to surrounding non-expressing cells in 12 individual wells. 82.11 $\pm 1.54 \%$ of the cells transfected with pICP0GFP and $79.37 \pm 4.92 \%$ of pcDNAICP0GFP-transfected cells were apoptotic, while only $6.23 \pm 2.33 \%$ of the cells transfected with pGFP were apoptotic. Cell lysates from transfected cells were assessed for the biochemical features of apoptosis via immunoblotting. pICP0GFP- and pcDNAICP0GFP-tranfected cells showed more PARP and caspase-7 cleavage than control pGFP (Figure 4B, compare lanes 1 and 2 with 3 ). These results indicate ICP0 expression leads to apoptosis in a cell autonomous manner in the HEp-2 cells.

\section{Full-Length ICPO Protein Is Not Required for Apoptosis Induction in HEp-2 Cells}

Previous studies showed that HSV-1 infected cells undergo HSV-dependent apoptosis when protein synthesis is inhibited and when both copies of genomic ICP0 contain a stop codon (Sanfilippo and Blaho, 2006). This finding suggests that the ICP0 RNA is a proapoptotic stimulus in infected HEp-2 cells. The next investigation was to determine whether partial ICP0 protein synthesis could facilitate $\alpha 0$ 's proapoptotic activity in HEp-2 cells. HEp-2 cells were transfected with a plasmid expressing a mutant of ICP0 with a nonsense mutation after codon 212, pTruncICP0 (Figure 1, line 8). The vector pUC19 was transfected as a negative control. The pBAK and pUC19 plasmids were used as positive and negative controls, respectively. At $24 \mathrm{~h}$ post-transfection, cellular and nuclear morphologies were assessed. This experiment was repeated in five times in triplicate. Phase contrast and Hoechst images from a representative experiment are displayed in Figure 5A. The overall means and standard deviations of chromatin condensation from all five experiments are graphed in Figure 5B. The cumulative results (Figure 5) were as follows. $14.07 \pm 10.7 \%$ of the pUC19-transfected cells showed chromatin condensation, which indicates a baseline level of apoptosis due to transfection. $61.7 \pm 22 \%$ of the pBAK-transfected cells exhibited chromatin condensation. Transfection of HEp-2 cells with pICP0 showed a statistically significant increased in chromatin condensation $(34.8 \pm 19.4 \%)$ compared to pUC19-transfected cells. Cells transfected with pTruncICP0 showed comparable amounts of chromatin condensation $(36.9 \pm 19.4 \%)$ to pICP0transfected cells.

Additionally, we assessed the biochemical markers of apoptosis by immunoblotting (Figure 5C). Procaspase-7 and the downstream caspase substrate PARP were used as markers for apoptosis. pUC19 transfection led to $30.53 \%$ PARP cleavage, showing background levels of apoptosis due to transfection 


\section{A Cellular and nuclear morphologies - HEp-2 cells at $24 \mathrm{~h}$ post transfection}
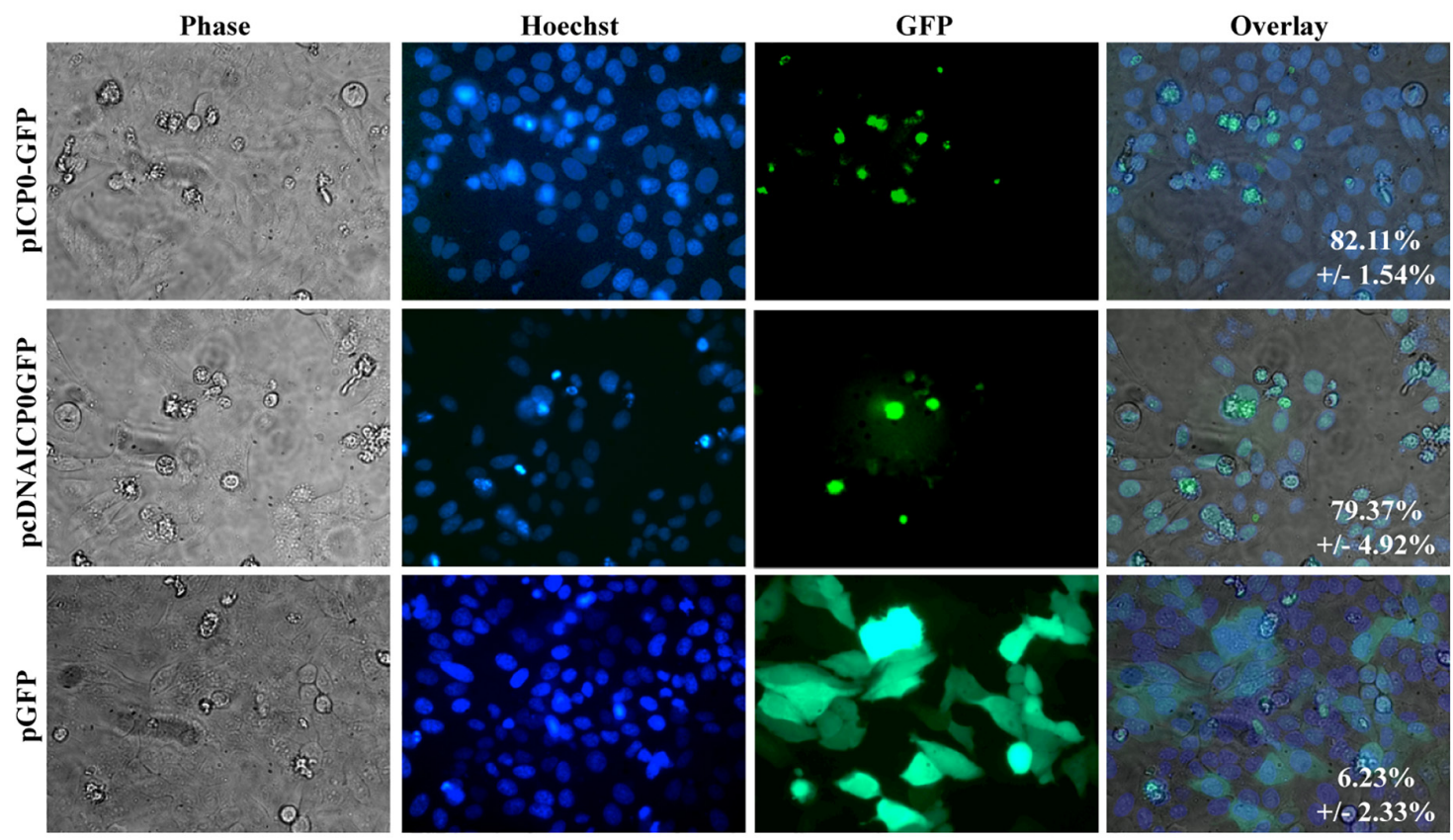

\section{B Immunoblots - viral and death factor proteins after transfection}

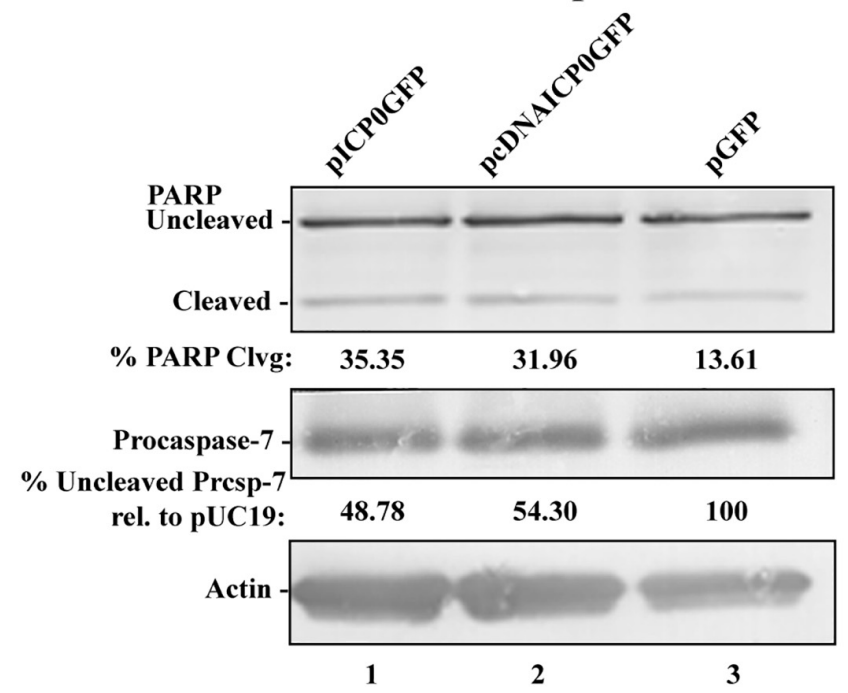

FIGURE 4 | Morphological and biochemical assessment of transfected HEp-2 cells at 24 h post-transfection. (A) Cell morphologies of HEp-2 cells transfected with $0.4 \mu \mathrm{g}$ of pICPOGFP, pcDNAICPOGFP, or pGFP. Fluorescence images were obtained to identify Hoechst DNA staining (Hoechst) and the presence of the GFP. Phase contrast, Hoechst-stained, and GFP images were layered to obtain a merged image (overlay). The numbers inside each frame refers to the percentage of GFP positive cells exhibiting condensed chromatin. (B) Whole-cell extracts of HEp-2 cells transfected with pICPOGFP, pcDNAICPOGFP, and a GFP expressing control plasmid (pGFP) were obtained from triplicate wells, separated in a denaturing gel, transferred to nitrocellulose, and probed with anti-PARP, -procaspase-7 and -actin antibodies. PARP and procaspase-7 band intensities were quantified using NIH image software, as described in Section "Materials and Methods." Percent PARP cleavage was calculated as a ratio of the band intensity of cleaved PARP relative to the sum of uncleaved and cleaved bands. For procaspase-7 protein, the band intensity for cells transfected with pUC19 was set to 100\% and all other groups are displayed relative to this number. Cropped images of blots were prepared as described in Section "Materials and Methods."

protocols. We set the levels of procaspase-7 protein present in this group to $100 \%$. pBAK-transfected cells displayed $49.7 \%$ PARP cleavage and $64.45 \%$ procaspase-7 protein relative to pUC19. This is consistent with the majority of cells undergoing apoptosis as based on the morphological assessment above. pICP0 - and pTruncICP0-transfected cells displayed similar levels of PARP cleavage (36.64 and 36.82\%, respectively) and procaspase- 7 protein ( 57.11 and $41.33 \%$, respectively). The above 
A Cellular and nuclear morphologies - HEp-2 cells at $24 \mathrm{~h}$ post transfection

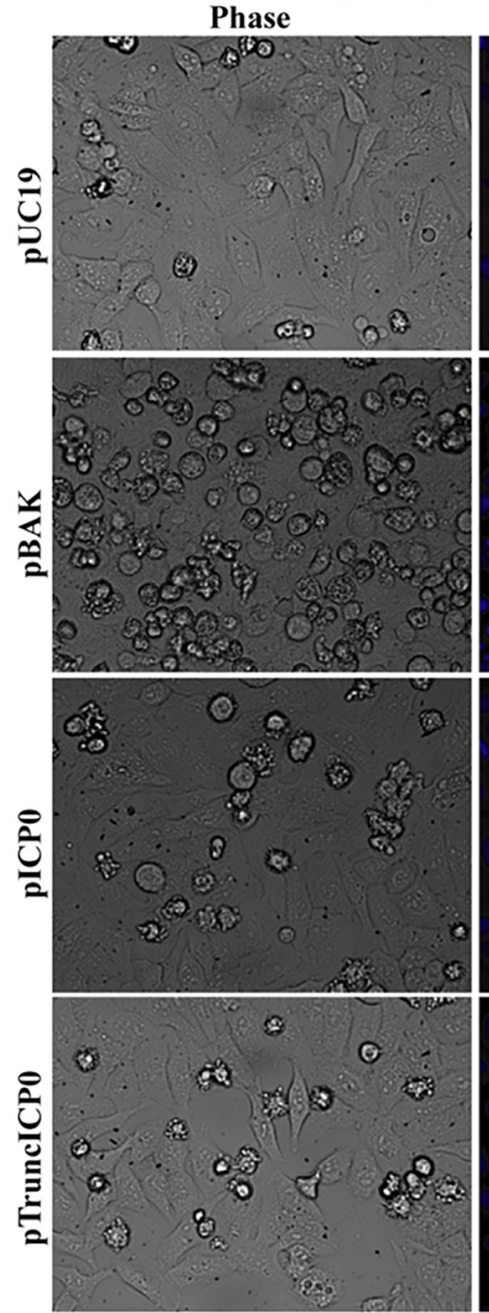

B Statistical analysis of condensed chromatin

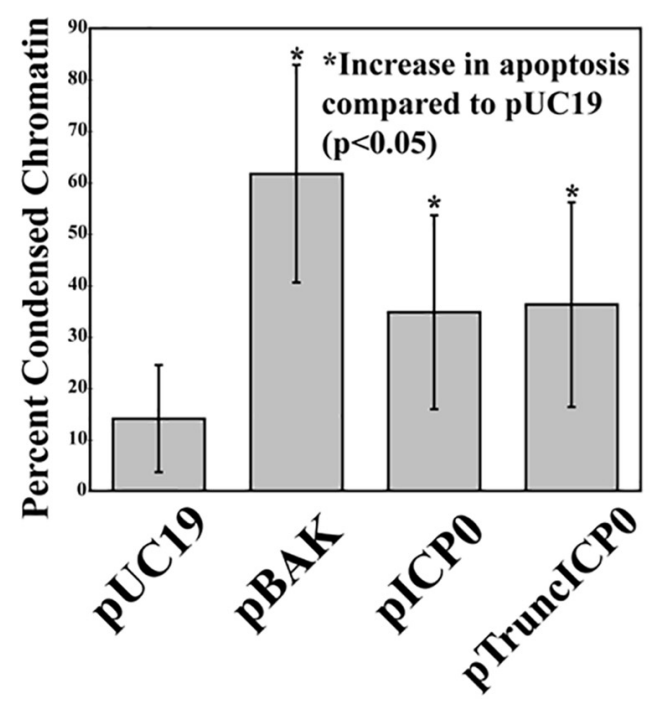

Hoechst
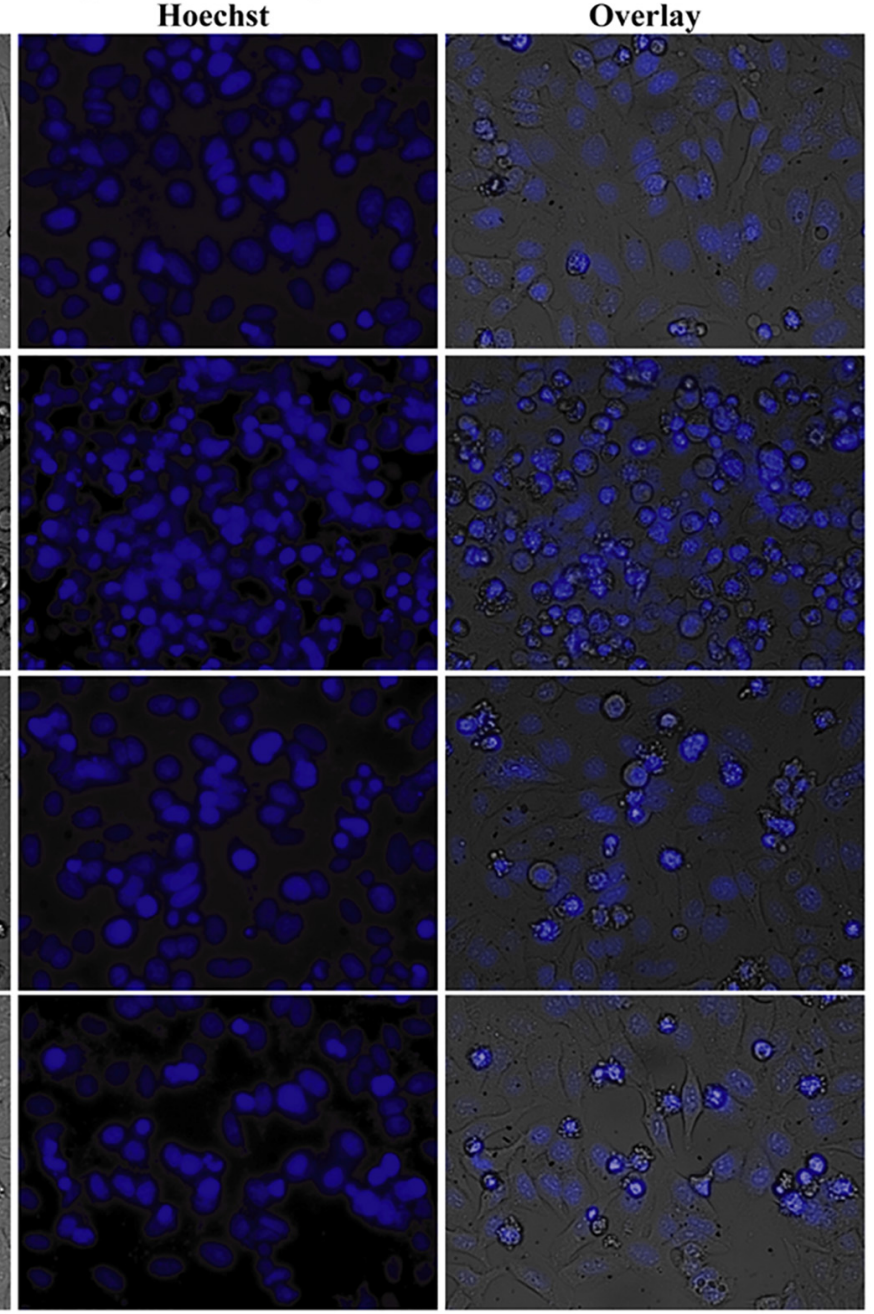

C Immunoblots - HEp-2 proteins after transfection

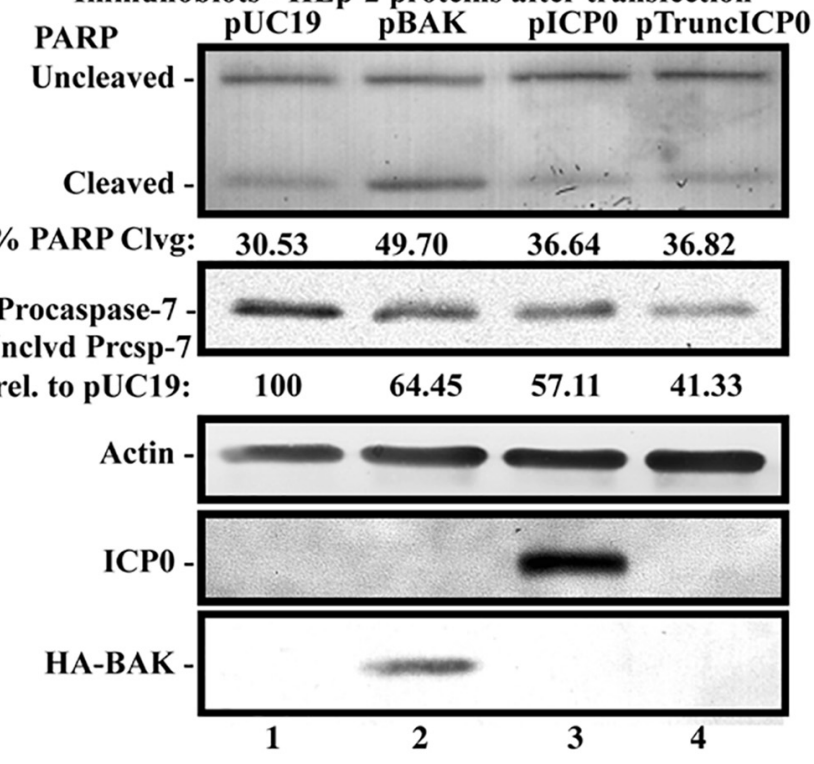


FIGURE 5 | Apoptosis in HEp-2 cells following transfection with pICPO and pTrunclCPO. (A) Cell morphologies of HEp-2 cells transfected with 0.4 $\mu$ g of pUC19, pBAK, pICPO, or pTruncICPO. Phase contrast, Hoechst and overlay images were captured with a digital camera (40X magnification). Images are representative of a single experiment. (B) Statistical analysis of percentages of condensed chromatin for each treatment was conducted using Student's $t$-test ( $p<0.05)$. The results represented in the bar graphs are from five independent experiments performed in triplicate. The mean of the percentage of cells exhibiting chromatin condensation following transfection is graphed. Error bars represent the standard deviation for each treatment group. (C) Immune reactivities of transfected cells from triplicate wells that were combined, harvested, separated in a denaturing gel, transferred to nitrocellulose, probed with anti-PARP, -procaspase-7, -ICPO, -actin, and -HA (to recognize HA-tagged BAK protein) primary antibodies. PARP and procaspase-7 band intensities were quantified using NIH image software, as described in Section "Materials and Methods." Percent PARP cleavage was calculated as a ratio of the band intensity of cleaved PARP relative to the sum of uncleaved and cleaved bands. For procaspase-7 protein, the band intensity for cells transfected with pUC19 was set to $100 \%$ and all other groups are displayed relative to this number. Cropped images of blots were prepared as described in Section "Materials and Methods."

morphological and biochemical results show that full-length ICP0 protein is not necessary for ICP0-induced apoptosis in transfected cells. These findings suggest other properties of the $\alpha 0$ gene may affect apoptosis induction in HEp- 2 cells.

\section{ICPO RNA Is Sufficient to Induce Apoptosis in HEp-2 Cells}

We next investigated the ability of ICP0 gene expression to induce apoptosis in the absence of ICP0 protein production in transfected cells HEp-2 cells. HEp-2 cells were transfected either with a plasmid expressing genomic $\alpha 0$ with two stop mutations after codons 12 and 106, p $\alpha 0$ RNA12/106, or after codons 12 and 212, pa0RNAn12/212 (Figure 1, lines 9 and 10). The vector pUC19 was transfected as a negative control, and pICP0 and pBAK were used as positive controls. At $24 \mathrm{~h}$ posttransfection, cellular and nuclear morphologies were assessed. This experiment was repeated in triplicate wells two times. Phase contrast and Hoechst images from a representative experiment are displayed in Figure 6A. The cumulative means and standard deviations of chromatin condensation from both experiments are graphed in Figure 6B. $5.1 \pm 2.2 \%$ of the pUC19-transfected cells showed chromatin condensation. $37.5 \pm 8.5 \%$ of the pBAKtransfected cells exhibited chromatin condensation. Transfection of HEp-2 cells with pICP0 showed a statistically significant increased in chromatin condensation $(22.9 \pm 5.4 \%)$ compared to pUC19-transfected cells. Cells transfected with p $\alpha 0$ RNAn12/106 and $\mathrm{p} \alpha 0 \mathrm{RNAn} 12 / 212$ showed comparable amounts of chromatin condensation to pICP0-transfected cells $(22.1 \pm 7.0$ and $20.6 \pm 6.2 \%$, respectively).

PARP and procaspase-7 cleavage were assessed for biochemical indication of apoptosis using immunoblotting (Figure 6C). pUC19 transfection leads to $18.01 \%$ PARP cleavage, showing background levels of apoptosis due to transfection protocols, and again we set the levels of procaspase-7 protein in this group to $100 \%$. pBAK-transfected cells displayed $35.34 \%$ PARP cleavage and $73.63 \%$ procaspase- 7 protein relative to pUC19, which is consistent with a significant portion of cells undergoing apoptosis as based on the morphological assessment above. pICP0-, pa0RNAn12/106- and p $\alpha 0$ RNAn12/212transfected cells displayed similar levels of PARP cleavage (27.78, 27.95 , and 27.96 , respectively) and procaspase-7 protein (88.15, 85.84 , and 88.75 , respectively).

Together, the above morphological and biochemical findings show that ICP0 protein is not necessary for ICP0-induced apoptosis in transfected cells. These results support previous findings which suggest that ICP0 RNA is responsible for HSV1-induced apoptosis in HEp-2 cells.

\section{ICP0 Protein Is Not Required for Autonomous Proapoptotic Activity in HEp-2 Cells}

Results above (Figure 4) indicate that transfection of the wildtype ICP0 gene causes apoptosis in a cell autonomous manner. To determine whether this was also true for $\alpha 0$ RNA expression alone the ICP0 open reading frame of pICP0GFP was replaced with $\alpha 0$ with two stop mutations after codons 12 and 106, p $\alpha 0$ RNA12/106, termed p $\alpha 0$ RNAn12/106GFP. This plasmid was transfected into HEp-2 cells; pcDNAICP0GFP, pICP0, and pGFP were transfected into cells as controls. At $24 \mathrm{~h}$ following transfection, GFP fluorescence, chromatin condensation, and morphological changes were assessed using phase and fluorescence microscopy (Figure 7). Green fluorescence indicative of GFP expression was evident in all transfected cells. The majority of the GFP positive cells from the pGFP transfection displayed cobblestone morphology and their chromatin was evenly distributed throughout the nuclei, indicative of a healthy cell monolayer, and similar to the morphologies of the surrounding non-transfected cells. In contrast, the majority of the GFP-positive cells from the pICP0GFP-, pcDNAICP0GFP-, and pa0RNAn12/106GFP-transfected wells were smaller, exhibited membrane blebbing, and displayed smaller, more brightly stained nuclei than surrounding non-transfected cells. These phenotypes are indicative of cells undergoing apoptosis. We quantified the percentage of GFP-positive cells displaying apoptotic morphologies to surrounding non-GFP-expressing cells in 12 individual wells. $80.01 \pm 5.67,97.53 \pm 2.50$, and $99.52 \pm 1.26 \%$ of the cells transfected with pcDNAICP0GFP, pICP0GFP, p $\alpha 0$ RNAn12/106GFP were apoptotic, while only $11.67 \pm 2.06 \%$ of the cells transfected with pGFP were apoptotic. Together, these results indicate that ICP0 protein is not required for the autonomous proapoptotic activity of $\alpha 0$ in HEp- 2 cells.

\section{A Nonsense Mutation at Amino Acid 212 Abrogates Apoptosis in Vero Cells}

Previously, we determined while infected HEp-2 cells can undergo HSV-dependent apoptosis in the absence of protein expression, infected Vero cells require expression of a protein facilitator for HSV-dependent apoptosis (Nguyen et al., 2005). Given that some form of infected cell protein synthesis was needed for apoptosis in infected Vero cells, it was possible that 
A Cellular and nuclear morphologies - HEp-2 cells at 24 h post transfection

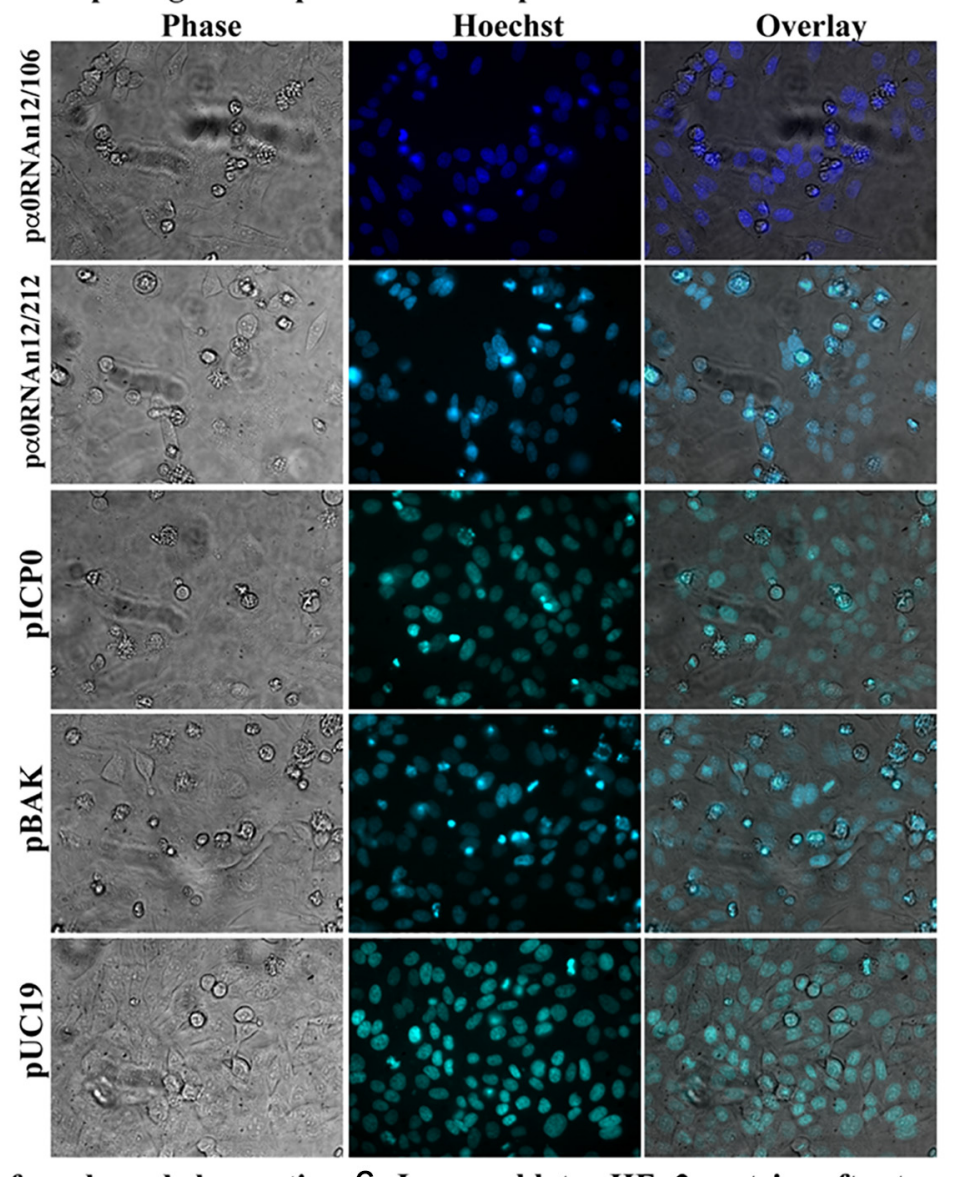

B Statistical analysis of condensed chromatin

C Immunoblots - HEp2 proteins after transfection

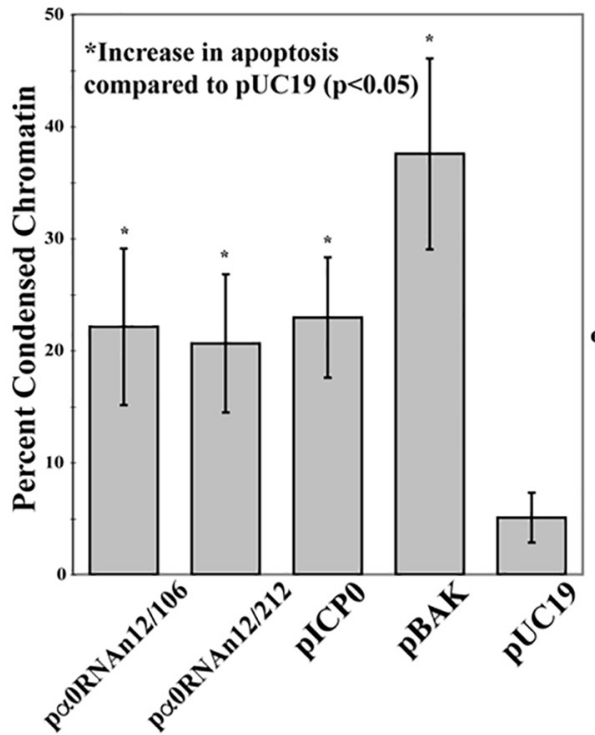
PARP pa.0RNAn12/106 pa.0RNAn12/212 pICP0 pBAK pUC19

Uncleaved

Cleaved -

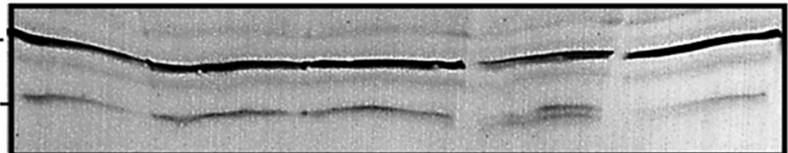

\% PARP Clvg: 27.78

27.95

27.96

35.34

18.01

Procaspase-7 -

\% Unclvd Presp-7

rel. to pUC19:

88.15

85.84

88.75

73.63

100

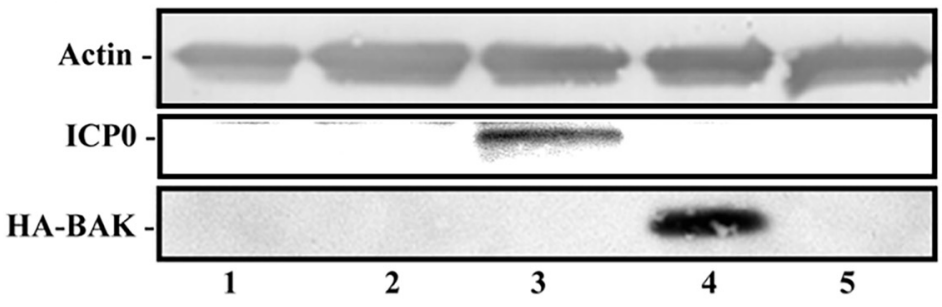

FIGURE 6 | Apoptosis in HEp-2 cells following transfection with paORNAn12/106, and paORNAn12/212. (A) Cell morphologies of HEp-2 cells transfected with $0.4 \mu \mathrm{g}$ of p $\alpha$ ORNAn12/106, paORNAn12/212, plCPO, pBAK, or pUC19. Phase contrast, Hoechst-stained, and overlayed images were captured with a digital camera (40X magnification). Images are representative of a single triplicate experiment. (B) Statistical analysis of percentages of condensed chromatin for each treatment was conducted using Student's $t$-test $(p<0.05)$. The results represented in the bar graphs are from five independent experiments performed in triplicate. The mean of the percentage of cells exhibiting chromatin condensation following transfection is graphed. Error bars represent standard deviation for each treatment group. 
FIGURE 6 | Continued

(C) Immune reactivities of transfected cells from triplicate wells that were combined, harvested, separated in a denaturing gel, transferred to nitrocellulose, probed with anti-PARP, -procaspase-7, -ICPO, -actin, and -HA primary antibodies. PARP and procaspase-7 band intensities were quantified using NIH image software, as described in Section "Materials and Methods." Percent PARP cleavage was calculated as a ratio of the band intensity of cleaved PARP relative to the sum of uncleaved and cleaved bands. For procaspase-7 protein, the band intensity for cells transfected with pUC19 was set to $100 \%$ and all other groups are displayed relative to this number. Cropped images of blots were prepared as described in Section "Materials and Methods."

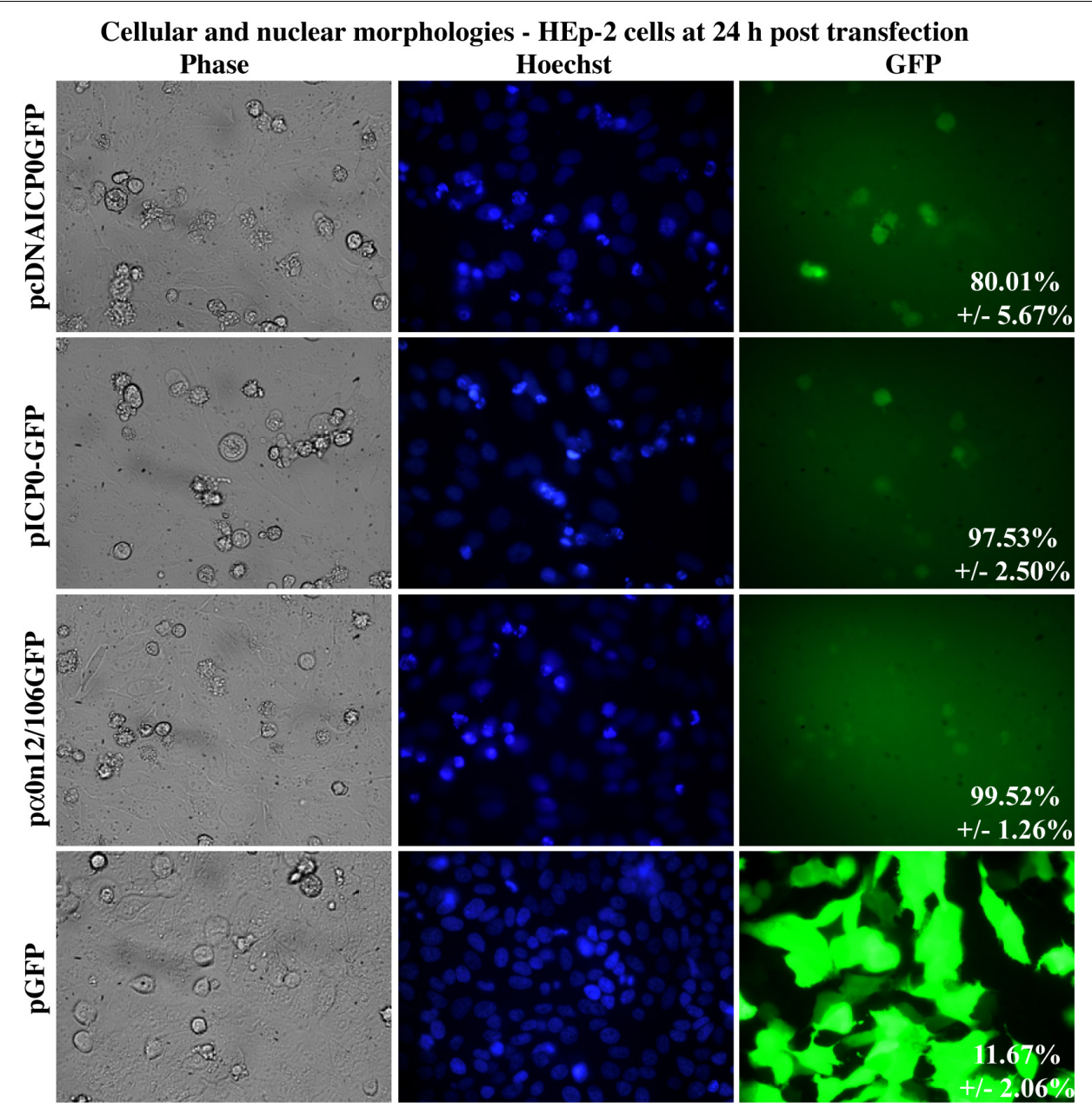

FIGURE 7 | Apoptosis in HEp-2 cells following transfection with paORNAn12/106GFP. Cell morphologies of HEp-2 cells transfected with 0.4 $\mu$ g of pcDNAICP0GFP, pICP0GFP, paORNAn12/106GFP, or pGFP. Phase contrast, Hoechst-stained, and overlayed images were captured with a digital camera (40X magnification). Images are representative of a single experiment and numbers inside the overlay represent the mean and standard deviation of the percentage of GFP positive cells displaying condensed chromatin in the given triplicate experiment.

it was the ICP0 protein itself that facilitates this viral apoptosis. To determine if full-length ICP0 protein was necessary for the $\alpha 0$ induced apoptosis, Vero cells were transfected with pTruncICP0. The pUC19 plasmid was used as a negative control and pICP0 and pBAK were used as positive controls. At 24, 36, 48, and $72 \mathrm{~h}$ post-transfection, cellular, and nuclear morphologies were assessed and the results from a representative experiment at $48 \mathrm{~h}$ post-transfection are shown in Figure 8A. Apoptotic percentages were determined by dividing the number of apoptotic cells by the total number of cells per image. To account for any minor variations in background levels of apoptosis throughout the timecourse, each treatment was divided by the apoptotic percentage of the pUC19 well for the given time point to calculate the fold increase in apoptosis from pUC19. The means and standard deviations for each timepoint were determined and displayed graphically in Figure 8B. pUC19-transfected cells showed little chromatin condensation (1.66 $\pm 0.92 \%)$. This indicates that the baseline level of apoptosis due to transfection for Vero cells is very low. The pBAK-transfected cells displayed chromatin condensation that was 6-12 fold higher than that of pUC19. Transfection of Vero cells with pICP0 showed a statistically significant increase in chromatin condensation 
A Cellular and nuclear morphologies - Vero cells at $48 \mathrm{~h}$ post transfection

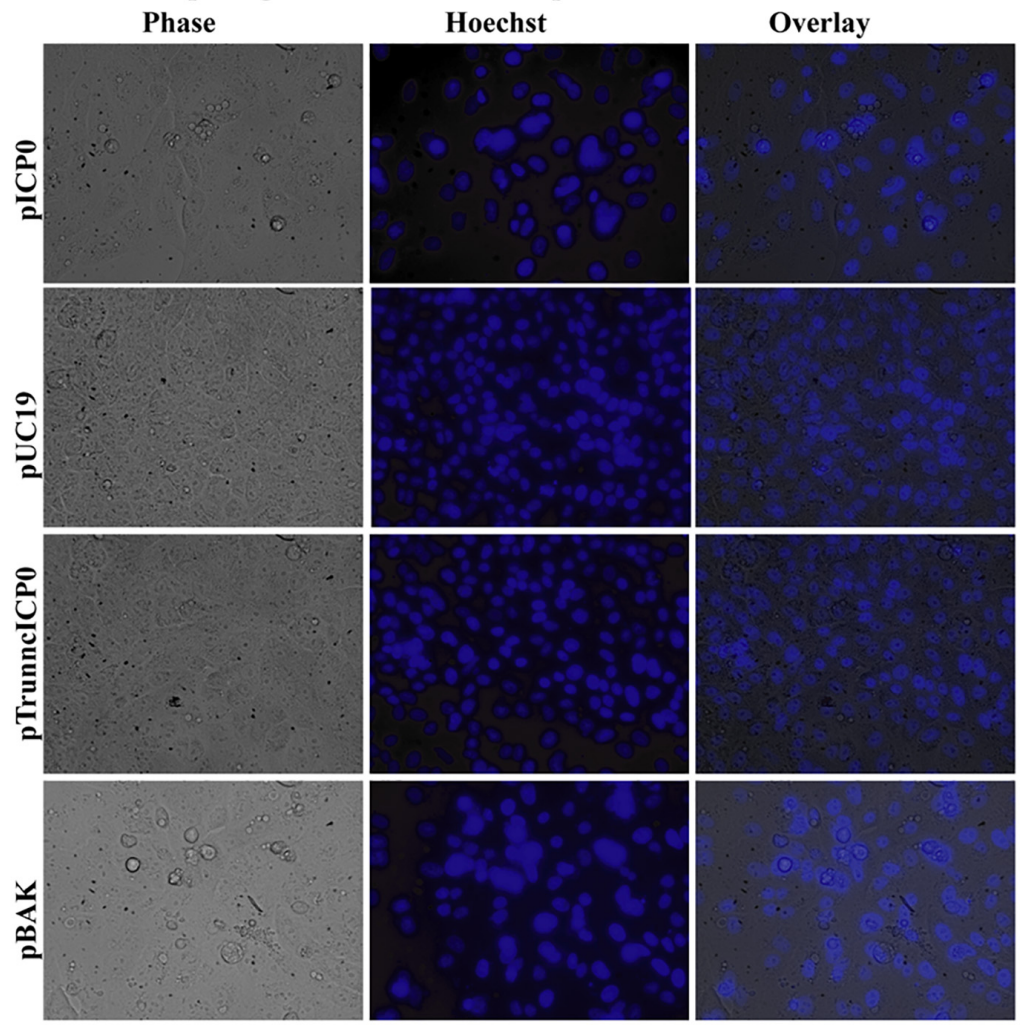

B Statistical analysis of condensed chromatin

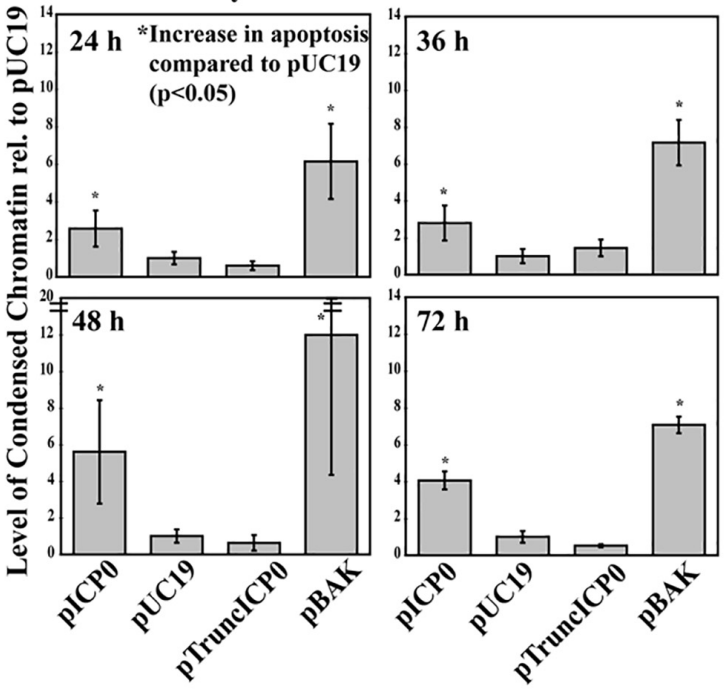

C Immunoblots - Vero proteins at $72 \mathrm{~h}$ post transfection

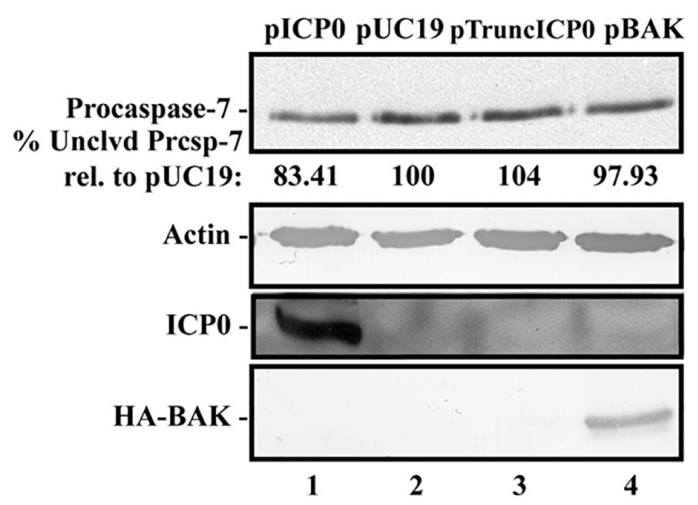

FIGURE 8 | Vero cells do not undergo apoptosis following transfection with pTrunclCPO. Vero cells were transfected with $1.0 \mu \mathrm{g}$ of pICPO, pUC19, pTrunclCPO, or pBAK and Hoechst DNA dye was added to the media at $23 \mathrm{~h}$ post-transfection. At 24, 36, 48, and $72 \mathrm{~h}$ post-transfection, phase contrast and fluorescence microscopy was used to visualize cellular and nuclear morphologies. (A) Phase contrast, Hoechst-stained, and overlay images were obtained at $48 \mathrm{~h}$ post-transfection (40X magnification). (B) The percentage of chromatin condensation at 24, 36, 48, and $72 \mathrm{~h}$ in triplicate wells was calculated for four independent experiments. The mean chromatin condensation percentage was calculated for each time point. The percentage of condensed chromatin in pUC19 treated cells was set to 1 for each time point and other groups are presented as a relative value compared to pUC19. The mean relative chromatin condensation is graphed. Error bars represent the standard deviation. Statistical analysis of percentages of condensed chromatin for each treatment and time point was conducted using Student's t-test. (C) Triplicate wells were combined at $72 \mathrm{~h}$ post-transfection and whole-cell extracts were obtained, separated in a denaturing gel, transferred to nitrocellulose, probed with anti-procaspase-7, -actin, -ICPO, -HA primary antibodies. The intensities of procaspase-7 bands were quantified using $\mathrm{NIH}$ image, as described in Section "Materials and Methods." For procaspase-7 protein, the band intensity for cells transfected with pUC19 was set to $100 \%$ and all other groups are displayed relative to this number. Cropped images of blots were prepared as described in Section "Materials and Methods." 
(2.6-5.6 times) compared to pUC19. Cells transfected with pTruncICP0 showed low levels of chromatin condensation (0.61.4) relative to $\mathrm{pUC19.}$

At $72 \mathrm{~h}$ post-transfection, whole-cell extracts from transfected cells were analyzed for apoptotic proteins, ICP0 and BAK using immunoblotting (Figure 8C). Lysates from pBAK-transfected cells exhibited detectable decreases in procaspase-7 protein (97.93\%) compared to pUC19. These findings show that Vero cells are more resistant to BAK-induced apoptosis than HEp2 cells. Transfection with pICP0 led to decreased levels of procaspase-7 (83.41\%) compared to pUC19 (100\%). pTruncICP0 transfection displayed little to no reduction of procaspase-7 levels (104\%) compared to pUC19. These results demonstrate that fulllength ICP0 protein is necessary for ICP0-induced apoptosis in transfected Vero cells. Based on these findings, we conclude that the facilitator protein must be either full-length ICP0 or a cellular protein that is dependent on ICP0.

\section{Apoptosis Is Cell-Autonomous in ICPO-Transfected Vero Cells}

In this final study, we assessed whether Vero cells expressing ICP0 were undergoing apoptosis themselves or if they were releasing proapoptotic factors causing death in surrounding non-transfected cells. To differentiate between these possibilities, Vero cells were transfected with pICP0GFP so we could identify the cells expressing ICP0 and assess their morphologies. Transfection with pGFP was used as a negative control. At $48 \mathrm{~h}$ post-transfection, Hoechst DNA dye was added to the media to allow for visualization of chromatin. Subsequent GFP fluorescence, chromatin condensation and morphological changes were assessed using phase and fluorescence microscopy (Figure 9). The GFP positive cells from the pGFP transfection were flat and well spread out, similar to surrounding nontransfected cells. Additionally, they displayed an evenly distributed nuclear Hoechst staining pattern, which is typical of healthy cells. The GFP-positive cells from the pICP0GFPtransfected wells displayed phenotypes indicative of cells undergoing apoptosis. We quantified the percentage of GFPpositive cells displaying apoptotic morphologies compared to surrounding non-expressing cells. $78.44 \pm 12.13 \%$ of the cells transfected with pICP0GFP were apoptotic. This result indicates that the cells are undergoing ICP0-dependent apoptosis do it in a cell autonomous manner. Thus, if a cellular protein is also involved in the apoptotic process in Vero cells, it does not likely migrate to surrounding cells.

\section{DISCUSSION}

A link between apoptosis and the latency of HSV is supported by many studies from multiple research groups. Therefore, studies of apoptosis in HSV infected cells is likely to provide insight into the establishment, maintenance, and reactivation from latency. Our previous studies have identified the $\alpha 0$ gene as the viral trigger of apoptosis during HSV infections. In this study, we set out to address several key unknowns. The first was focused on the structure of the $\alpha 0$ gene in apoptosis induction in HEp2 cells. The second involved whether this process occurred in a cell autonomous manner. Finally, we investigated the role of ICP0 protein in apoptosis in Vero cells. Our key findings may be summarized as follows.

ICP0 is sufficient to serve as the herpes apoptosis facilitator (HDAP) in Vero cells. This does not exclude the possibility that other cellular proteins may also be involved. This finding is consistent with previous studies (Inman et al., 2001b) and may be related to the noted ICP0 toxicity in viral gene therapy vectors (Samaniego et al., 1998). The key question remains about the basis of the difference between HEp-2 and Vero cells

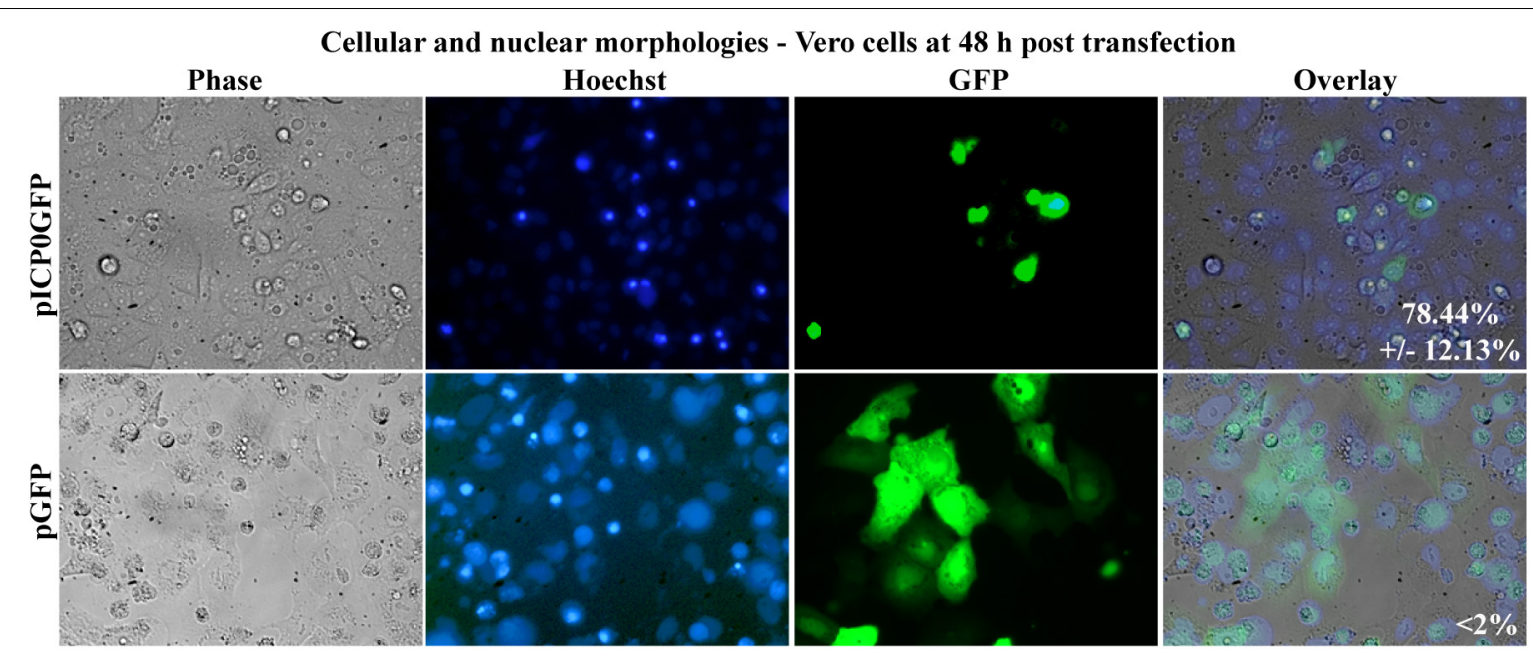

FIGURE 9 | Apoptosis in Vero cells following transfection with pICPOGFP. Cell morphologies of Vero cells transfected with $0.4 \mu \mathrm{g}$ of pICP0GFP or pGFP. Phase contrast, Hoechst-stained, and overlayed images were captured with a digital camera (40X magnification). Images are representative of a single experiment and numbers inside the overlay represent the mean and standard deviation of the percentage of GFP positive cells displaying condensed chromatin quantified in the given triplicate experiment. 
in the requirements for apoptosis induction. HEp-2 cells are transformed cells and fail to express p53, due to the presence of the human papillomavirus E6 protein (Ogura et al., 1993), which has been previously shown to influence HSV-dependent apoptosis (Nguyen et al., 2007). Vero cells are immortalized, but not transformed; this distinction appears to imply that the proapoptotic activity of ICP0 may be affected by p53 status. Previous reports have shown that ICP0 can mediate the ubiquitination of p53 by acting as a RING finger ubiquitin E3 ligase (Boutell and Everett, 2003). Interestingly, a recent study described a reduced replication of $\mathrm{HSV}-1$ in $\mathrm{p} 53$ deficient cells. They also reported that the ICP0 protein itself could be degraded in a p53dependent manner in cells and that this was inhibited during a wild-type infection by ICP22 (Maruzuru et al., 2013), suggesting that a complex interplay between ICP0 and p53 may exist during HSV-1 infection.

$\alpha 0$-Dependent apoptosis likely plays a role during HSV reactivation from latency. ICP0 is essential for viral replication upon reactivation from HSV latency (Leib et al., 1989b). It is now recognized that VP16 is key to reactivation (Kim et al., 2012; Sawtell and Thompson, 2016). $\alpha 0$ is the first viral gene transcribed by VP16 (Harris-Hamilton and Bachenheimer, 1985). That both $\alpha 0$ RNA and ICP0 protein are proapoptotic in certain cells, raises the possibility that neuronal apoptosis occurs during reactivation. This might explain previous observations of apoptosis in herpes encephalitis (DeBiasi et al., 2002).

Although the LATs and miRNA of HSV are the only HSV gene products found to be abundantly expressed during latency, previous studies have detected low levels of $\alpha 0$ transcripts during HSV latency (Chen et al., 2002; Pesola et al., 2005; Maillet et al., 2006). A recent study by Raja and colleagues indicated that interruption of ICP0 expression led to reduced association of viral genomes with histones and lower levels of LAT transcripts in a murine latency model (Raja et al., 2016). The authors of this study propose a model in which low levels of ICP0 protein expression contribute to the establishment and/or maintenance of latency by facilitating genome association with heterochromatin and enhancing LAT expression. It is possible that ICP0's proapoptotic functions may also contribute to this newly identified role for ICP0 in establishment and maintenance of latency.

Together, this study has determined that the $\alpha 0$ gene produces two pro-apoptotic gene products during HSV infection. The $\alpha 0$ transcript is sufficient for apoptosis induction in at least one cell line, HEp-2 cells. On the other hand, other cell types, e.g., Vero cells, require both the transcript and protein of the

\section{REFERENCES}

Ahmed, M., Lock, M., Miller, C. G., and Fraser, N. W. (2002). Regions of the herpes simplex virus type 1 latency-associated transcript that protect cells from apoptosis in vitro and protect neuronal cells in vivo. J. Virol. 76, 717-729. doi: 10.1128/jvi.76.2.717-729. 2002

Aubert, M., and Blaho, J. A. (1999). The herpes simplex virus type 1 regulatory protein ICP27 is required for the prevention of apoptosis in infected human cells. J. Virol. 73, 2803-2813.

Aubert, M., Pomeranz, L. E., and Blaho, J. A. (2007). Herpes simplex virus blocks apoptosis by precluding mitochondrial cytochrome $\mathrm{c}$ release independent of
ICP0 open reading frame to trigger HSV-dependent apoptosis. It is important to note that primary human keratinocytes, the first cells that the virus usually interacts with, are susceptible to HSV-dependent apoptosis (Pradhan and Nguyen, 2013). Further investigation into $\alpha 0$-dependent apoptosis may allow for an improved understanding of the control of both latent and lytic HSV-1 infections. The ICP0 protein is necessary for viral replication upon reactivation (Leib et al., 1989b). Additionally, a recent study has reported that disruption of ICP0 expression led to reduced LAT transcript levels (Raja et al., 2016). Thus, both apoptosis regulation and $\alpha 0$ gene expression have been implicated in latency regulation. Investigators seeking to understanding the role of ICP0 in HSV latency most now consider the potential that both $\alpha 0$ RNA and protein may trigger apoptosis as part of the reactivation process.

\section{AUTHOR CONTRIBUTIONS}

MN and JB designed, supervised, and interpreted the experiments and finalized the figures and manuscript. EG and KP performed the experiments as research coordinators. EG organized the original figures and wrote an initial version of the manuscript.

\section{FUNDING}

These studies were supported in part by a grant from the USPHS (AI48582 to JB). MN was supported in part by USPHS Institutional Research Training Awards (AI07647 and CA088796). KP was supported in part by an Undergraduate Research Fellowship from the Howard Hughes Medical Institute to Manhattan College, Riverdale, NY, United States. JB acknowledges the NYCRIN and CUNY I-Corps support of the National Science Foundation (Award Nos. OIA-1305023, IPP1644664, and IIP-1740622).

\section{ACKNOWLEDGMENTS}

We thank Elise Morton and Leah Kang (MSSM) for expert technical cell culture assistance and Saul Silverstein, Priscilla Schaffer, Mary Klotman, and Peter Palese for providing reagents. We wish to dedicate this paper to the memory of Priscilla Schaffer who was always so helpful and supportive of our work.

caspase activation in infected human epithelial cells. Apoptosis 12, 19-35. doi: 10.1007/s10495-006-0330-3

Blaho, J. A., Mitchell, C., and Roizman, B. (1994). An amino acid sequence shared by the herpes simplex virus 1 alpha regulatory proteins $0,4,22$, and 27 predicts the nucleotidylylation of the UL21, UL31, UL47, and UL49 gene products. J. Biol. Chem. 269, 17401-17410.

Boutell, C., and Everett, R. D. (2003). The herpes simplex virus type 1 (HSV-1) regulatory protein ICP0 interacts with and Ubiquitinates p53. J. Biol. Chem. 278, 36596-36602. doi: 10.1074/jbc.m300776200

Cai, W. Z., and Schaffer, P. A. (1989). Herpes simplex virus type 1 ICP0 plays a critical role in the de novo synthesis of infectious virus following transfection of viral DNA. J. Virol. 63, 4579-4589. 
Carter, K. L., and Roizman, B. (1996). Alternatively spliced mRNAs predicted to yield frame-shift proteins and stable intron 1 RNAs of the herpes simplex virus 1 regulatory gene alpha 0 accumulate in the cytoplasm of infected cells. Proc. Natl. Acad. Sci. U.S.A. 93, 12535-12540. doi: 10.1073/pnas.93.22. 12535

Chen, S. H., Lee, L. Y., Garber, D. A., Schaffer, P. A., Knipe, D. M., and Coen, D. M. (2002). Neither LAT nor open reading frame $P$ mutations increase expression of spliced or intron-containing ICP0 transcripts in mouse ganglia latently infected with herpes simplex virus. J. Virol. 76, 4764-4772. doi: 10.1128/jvi.76.10.47644772.2002

DeBiasi, R. L., Kleinschmidt-DeMasters, B. K., Richardson-Burns, S., and Tyler, K. L. (2002). Central nervous system apoptosis in human herpes simplex virus and cytomegalovirus encephalitis. J. Infect. Dis. 186, 1547-1557. doi: 10.1086/ 345375

Du, T., Zhou, G., and Roizman, G. (2012). Induction of apoptosis accelerates reactivation of latent HSV-1 in ganglionic organ cultures and replication in cell cultures. Proc. Natl. Acad. Sci. U.S.A. 109, 14616-14621. doi: 10.1073/pnas. 1212661109

Everett, R. D. (2000). ICP0, a regulator of herpes simplex virus during lytic and latent infection. Bioessays 22, 761-770. doi: 10.1002/1521-1878(200008)22: $8<761$ ::aid-bies10>3.0.co;2-a

Goodkin, M. L., Ting, A. T., and Blaho, J. A. (2003). NF-kappaB is required for apoptosis prevention during herpes simplex virus type 1 infection. J. Virol. 77, 7261-7280. doi: $10.1128 /$ jvi.77.13.7261-7280.2003

Hagglund, R., and Roizman, B. (2004). Role of ICP0 in the strategy of conquest of the host cell by herpes simplex virus 1. J. Virol. 78, 2169-2178. doi: 10.1128/jvi. 78.5.2169-2178.2004

Harris-Hamilton, E., and Bachenheimer, S. L. (1985). Accumulation of herpes simplex virus type 1 RNAs of different kinetic classes in the cytoplasm of infected cells. J. Virol. 53, 144-151.

Inman, M., Perng, G. C., Henderson, G., Ghiasi, H., Nesburn, A. B., Wechsler, S. L., et al. (2001a). Region of herpes simplex virus type 1 latency-associated transcript sufficient for wild-type spontaneous reactivation promotes cell survival in tissue culture. J. Virol. 75, 3636-3646. doi: 10.1128/jvi.75.8.36363646.2001

Inman, M., Zhang, Y., Geiser, V., and Jones, C. (2001b). The zinc ring finger in the bICP0 protein encoded by bovine herpesvirus-1 mediates toxicity and activates productive infection. J. Gen. Virol. 82(Pt 3), 483-492. doi: 10.1099/0022-131782-3-483

Jin, L., Carpenter, D., Moerdyk-Schauwecker, M., Vanarsdall, A. L., Osorio, N., Hsiang, C., et al. (2008). Cellular FLIP can substitute for the herpes simplex virus type 1 latency-associated transcript gene to support a wild-type virus reactivation phenotype in mice. J. Neurovirol. 14, 389-400. doi: 10.1080/ 13550280802216510

Jin, L., Peng, W., Perng, G. C., Brick, D. J., Nesburn, A. B., Jones, C., et al. (2003). Identification of herpes simplex virus type 1 latency-associated transcript sequences that both inhibit apoptosis and enhance the spontaneous reactivation phenotype. J. Virol. 77, 6556-6561. doi: 10.1128/jvi.77.11.6556-6561.2003

Jin, L., Perng, G. C., Mott, K. R., Osorio, N., Naito, J., Brick, D. J., et al. (2005). A herpes simplex virus type 1 mutant expressing a baculovirus inhibitor of apoptosis gene in place of latency-associated transcript has a wild-type reactivation phenotype in the mouse. J. Virol. 79, 12286-12295. doi: 10.1128/ jvi.79.19.12286-12295.2005

Kerr, J. F., Wyllie, A. H., and Currie, A. R. (1972). Apoptosis: a basic biological phenomenon with wide-ranging implications in tissue kinetics. Br. J. Cancer 26, 239-257. doi: 10.1038/bjc.1972.33

Kim, J. Y., Mandarino, A., Chao, M. V., Mohr, I., and Wilson, A. C. (2012). Transient reversal of episome silencing precedes VP16-dependent transcription during reactivation of latent HSV-1 in neurons. PLoS Pathog. 8:e1002540. doi: 10.1371/journal.ppat.1002540

Koyama, A. H., Adachi, A., and Irie, H. (2003). Physiological significance of apoptosis during animal virus infection. Int. Rev. Immunol. 22, 341-359. doi: $10.1080 / 08830180305210$

Kraft, R. M., Nguyen, M. L., Yang, X. H., Thor, A. D., and Blaho, J. A. (2006). Caspase 3 activation during herpes simplex virus 1 infection. Virus Res. 120, 163-175. doi: 10.1016/j.virusres.2006.03.003

Leib, D. A., Bogard, C. L., Kosz-Vnenchak, M., Hicks, K. A., Coen, D. M., Knipe, D. M., et al. (1989a). A deletion mutant of the latency-associated transcript of herpes simplex virus type 1 reactivates from the latent state with reduced frequency. J. Virol. 63, 2893-2900.

Leib, D. A., Coen, D. M., Bogard, C. L., Hicks, K. A., Yager, D. R., Knipe, D. M., et al. (1989b). Immediate-early regulatory gene mutants define different stages in the establishment and reactivation of herpes simplex virus latency. J. Virol. $63,759-768$.

Liesegang, T. J., Melton, L. J., Daly, P. J., and Ilstrup, D. M. (1989). Epidemiology of ocular herpes simplex. Incidence in Rochester, Minn, 1950 through 1982. Arch. Ophthalmol. 107, 1155-1159.

Maillet, S., Naas, T., Crepin, S., Roque-Afonso, A. M., Lafay, F., Efstathiou, S., et al. (2006). Herpes simplex virus type 1 latently infected neurons differentially express latency-associated and ICP0 transcripts. J. Virol. 80, 9310-9321. doi: 10.1128/jvi.02615-05

Maruzuru, Y., Fujii, H., Oyama, M., Kozuka-Hata, H., Kato, A., and Kawaguchi, Y. (2013). Roles of p53 in herpes simplex virus 1 replication. J. Virol. 87, 9323-9332. doi: 10.1128/JVI.01581-13

Nguyen, M. L., and Blaho, J. A. (2007). Apoptosis during herpes simplex virus infection. Adv. Virus Res. 69, 67-97. doi: 10.1016/s0065-3527(06)69002-7

Nguyen, M. L., and Blaho, J. A. (2009). Cellular players in the herpes simplex virus dependent apoptosis balancing act. Viruses 1, 965-978. doi: 10.3390/v1030965

Nguyen, M. L., Kraft, R. M., Aubert, M., Goodwin, E., DiMaio, D., and Blaho, J. A. (2007). p53 and hTERT determine sensitivity to viral apoptosis. J. Virol. 81, 12985-12995. doi: 10.1128/jvi.01485-07

Nguyen, M. L., Kraft, R. M., and Blaho, J. A. (2005). African green monkey kidney Vero cells require de novo protein synthesis for efficient herpes simplex virus 1-dependent apoptosis. Virology 336, 274-290. doi: 10.1016/j.virol.2005.03.026

Ogura, H., Yoshinouchi, M., Kudo, T., Imura, M., Fujiwara, T., and Yabe, Y. (1993). Human papillomavirus type 18 DNA in so-called HEP-2, KB and FL cellsfurther evidence that these cells are HeLa cell derivatives. Cell. Mol. Biol. 39, 463-467.

Panagiotidis, C. A., Lium, E. K., and Silverstein, S. J. (1997). Physical and functional interactions between herpes simplex virus immediate-early proteins ICP4 and ICP27. J. Virol. 71, 1547-1557.

Peña, K. C., Adelson, M. E., Mordechai, E., and Blaho, J. A. (2010). Genital herpes simplex virus type 1 in women: detection in cervicovaginal specimens from gynecological practices in the United States. J. Clin. Microbiol. 48, 150-153. doi: 10.1128/JCM.01336-09

Perng, G. C., Jones, C., Ciacci-Zanella, J., Stone, M., Henderson, G., Yukht, A., et al. (2000). Virus-induced neuronal apoptosis blocked by the herpes simplex virus latency-associated transcript. Science 287, 1500-1503. doi: 10.1126/science.287. 5457.1500

Perng, G. C., Maguen, B., Jin, L., Mott, K. R., Osorio, N., Slanina, S. M., et al. (2002). A gene capable of blocking apoptosis can substitute for the herpes simplex virus type 1 latency-associated transcript gene and restore wild-type reactivation levels. J. Virol. 76, 1224-1235. doi: 10.1128/jvi.76.3.1224-1235.2002

Pesola, J. M., Zhu, J., Knipe, D. M., and Coen, D. M. (2005). Herpes simplex virus 1 immediate-early and early gene expression during reactivation from latency under conditions that prevent infectious virus production. J. Virol. 79, 14516-14525. doi: 10.1128/jvi.79.23.14516-14525.2005

Phelan, D., Barrozo, E. R., and Bloom, D. C. (2017). HSV1 latent transcription and non-coding RNA: a critical retrospective. J. Neuroimmunol. 308, 65-101. doi: 10.1016/j.jneuroim.2017.03.002

Pradhan, P., and Nguyen, M. L. (2013). Early passage neonatal and adult keratinocytes are sensitive to apoptosis induced by infection with an ICP27-null mutant of herpes simplex virus 1. Apoptosis 18, 160-170. doi: 10.1007/s10495012-0773-7

Raja, P., Lee, J. S., Pan, D., Pesola, J. M., Coen, D. M., and Knipe, D. M. (2016). A herpesviral lytic protein regulates the structure of latent viral chromatin. mBio 7:e633-16. doi: 10.1128/mBio.00633-16

Salvesen, G. S., and Dixit, V. M. (1997). Caspases: intracellular signaling by proteolysis. Cell 91, 443-446. doi: 10.1016/s0092-8674(00)80430-4

Samaniego, L. A., Neiderhiser, L., and DeLuca, N. A. (1998). Persistence and expression of the herpes simplex virus genome in the absence of immediateearly proteins. J. Virol. 72, 3307-3320.

Sanfilippo, C. M., and Blaho, J. A. (2003). The facts of death. Int. Rev. Immunol. 22, $327-340$.

Sanfilippo, C. M., and Blaho, J. A. (2006). ICP0 gene expression is a herpes simplex virus type 1 apoptotic trigger. J. Virol. 80, 6810-6821. doi: 10.1128/jvi.00334-06 
Sanfilippo, C. M., Chirimuuta, F. N., and Blaho, J. A. (2004a). Herpes simplex virus type 1 immediate-early gene expression is required for the induction of apoptosis in human epithelial HEp-2 cells. J. Virol. 78, 224-239. doi: 10.1128/ jvi.78.1.224-239.2004

Sanfilippo, C. M., Lombardozzi, R. C., Chirimuuta, F. N., and Blaho, J. A. (2004b). Herpes simplex virus 1 infection is required to produce ICP27 immunoreactive triplet forms when ribosomal aminoacyl-tRNA translocation is blocked by cycloheximide. Virology 324, 554-566. doi: 10.1016/j.virol.2004. 04.011

Sawtell, N. M., and Thompson, R. L. (1992). Rapid in vivo reactivation of herpes simplex virus in latently infected murine ganglionic neurons after transient hyperthermia. J. Virol. 66, 2150-2156.

Sawtell, N. M., and Thompson, R. L. (2016). De novo herpes simplex virus VP16 expression gates a dynamic programmatic transition and sets the latent/lytic balance during acute infection in trigeminal Ganglia. PLoS Pathog. 12:e1005877. doi: 10.1371 /journal.ppat.1005877

Spivack, J. G., and Fraser, N. W. (1988). Expression of herpes simplex virus type 1 latency-associated transcripts in the trigeminal ganglia of mice during acute infection and reactivation of latent infection. J. Virol. 62, 1479-1485.

Stevens, J. G., Wagner, E. K., Devi-Rao, G. B., Cook, M. L., and Feldman, L. T. (1987). RNA complementary to a herpesvirus alpha gene mRNA is prominent in latently infected neurons. Science 235, 1056-1059. doi: 10.1126/science. 2434993
Takano, Y. S., Harmon, B. V., and Kerr, J. F. (1991). Apoptosis induced by mild hyperthermia in human and murine tumour cell lines: a study using electron microscopy and DNA gel electrophoresis. J. Pathol. 163, 329-336. doi: 10.1002/ path. 1711630410

Thompson, R. L., and Sawtell, N. M. (1997). The herpes simplex virus type 1 latency-associated transcript gene regulates the establishment of latency. J. Virol. 71, 5432-5440.

Villa, P., Kaufmann, S. H., and Earnshaw, W. C. (1997). Caspases and caspase inhibitors. Trends Biochem. Sci. 22, 388-393. doi: 10.1016/s0968-0004(97) 01107-9

Wyllie, A. H., Kerr, J. F., and Currie, A. R. (1980). Cell death: the significance of apoptosis. Int. Rev. Cytol. 68, 251-306. doi: 10.1016/s0074-7696(08)62312-8

Conflict of Interest Statement: The authors declare that the research was conducted in the absence of any commercial or financial relationships that could be construed as a potential conflict of interest.

Copyright (c) 2019 Nguyen, Gennis, Pena and Blaho. This is an open-access article distributed under the terms of the Creative Commons Attribution License (CC BY). The use, distribution or reproduction in other forums is permitted, provided the original author(s) and the copyright owner(s) are credited and that the original publication in this journal is cited, in accordance with accepted academic practice. No use, distribution or reproduction is permitted which does not comply with these terms. 